Volume 6, Issue 1 (Winter 2014)

\title{
Insights from Technical Analysis on a Group of Paintings by Gerrit Dou in the Leiden Collection
}

Dominique Surh, Ilona van Tuinen, John Twilley

Recommended Citation:

Dominique Surh, Ilona van Tuinen, John Twilley, "Insights from Technical Analysis on a Group of Paintings by Gerrit Dou in the Leiden Collection," JHNA 6:1 (Winter 2014), DOI:10.5092/ jhna.2014.6.1.3

Available at https://jhna.org/articles/insights-technical-analysis-group-of-paintings-gerrit-dou-leiden-collection/

Published by Historians of Netherlandish Art: https://hnanews.org/

Republication Guidelines: https://jhna.org/republication-guidelines/

Notes: This PDF is provided for reference purposes only and may not contain all the functionality or features of the original, online publication. This is a revised PDF that may contain different page numbers from the previous version. Use electronic searching to locate passages. This PDF provides paragraph numbers as well as page numbers for citation purposes.

ISSN: 1949-9833 


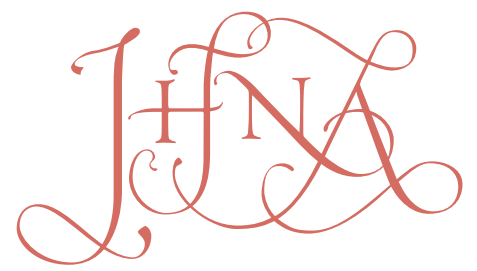

\title{
INSIGHTS FROM TECHNICAL ANALYSIS ON A GROUP OF PAINTINGS BY GERRIT DOU IN THE LEIDEN COLLECTION
}

\author{
Dominique Surh, Ilona van Tuinen, John Twilley
}

Over the past four years an inquiry has been conducted into the painting methods and materials employed by Gerrit Dou on a group of thirteen paintings in the Leiden Collection, New York, that spans the career of the artist. The study incorporates the results of diagnostic imaging by infrared techniques and X-radiography, analysis of selective pigment samples, dendrochronology of the support panels, and microscopic examination of Dou's paint handling and sequences of application. The study has brought to light numerous revisions by the artist in developing these compositions, some of which shed light on more fundamental issues of meaning in the depictions. 10.5092/jhna.2014.6.1.3
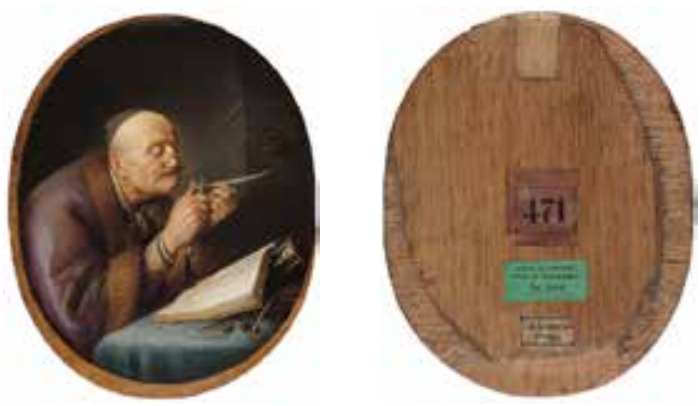

Figs. 1a-b (a) Gerrit Dou, Scholar Sharpening a Quill, ca. 1630-35, oil on panel, $25 \times 20.5 \mathrm{~cm}$, oval, signed, center right, under quill, "GD" (GD in ligature). The Leiden Collection, New York, GD-104 (b) verso
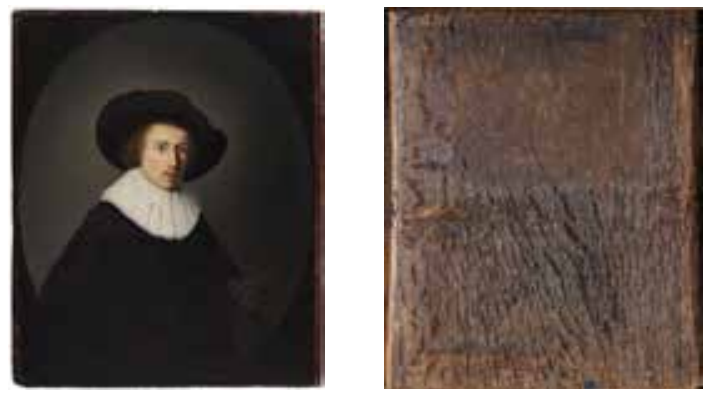

Fig. 3a Gerrit Dou, Portrait of a Young Man with a Hat, ca. 1635, oil on panel, $38 \times 30.5 \mathrm{~cm}$. The Leiden Collection, New York, GD-100 (b) verso
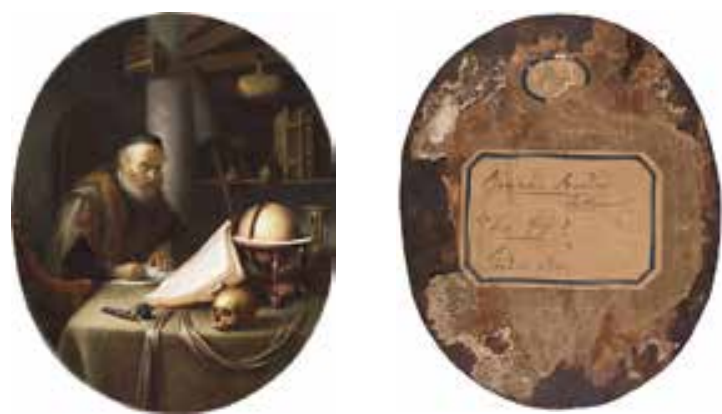

Fig. 2a Gerrit Dou, Scholar Interrupted at His Writing, ca. 1635, oil on panel, $24.5 \times 20 \mathrm{~cm}$, oval, signed, on a piece of paper protruding from the book, "GDov" (GD in ligature). The Leiden Collection, New York, GD-102 (b) verso
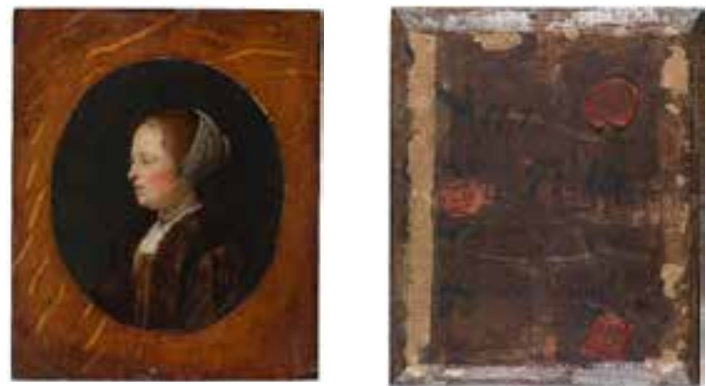

Fig. 4a Gerrit Dou, Portrait of a Lady in Profile, ca. 1635-40, oil on panel, oval inlaid into a rectangular panel, $13.3 \times 11.3 \mathrm{~cm}$, signed, left center, "GDou" (GD in ligature). The Leiden Collection, New York, GD-110 (b) verso 

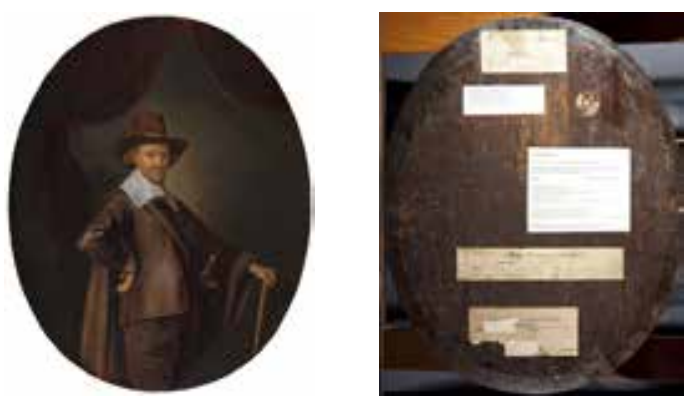

Fig. 5a Gerrit Dou, Portrait of a Gentleman with a Walking Stick, ca. 1645 , oil on panel, $49.2 \times 39.7 \mathrm{~cm}$, signed, right, "GDou" (GD in ligature). The Leiden Collection, New York, GD-113 (b) verso
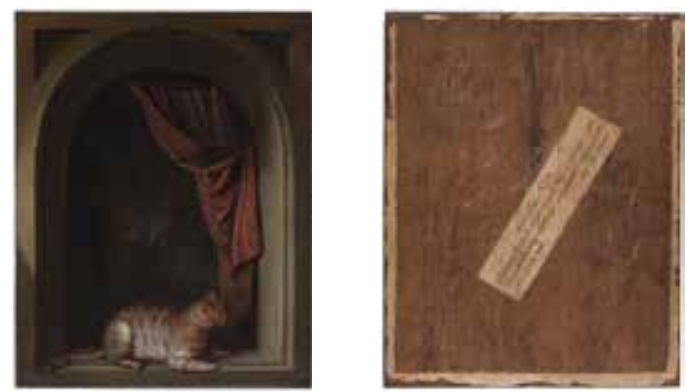

Figs. 7a-b (a) Gerrit Dou, Cat Crouching on the Ledge of an Artist's Atelier, 1657, oil on panel, $34 \times 26.7 \mathrm{~cm}$, signed and dated, on the ledge, "GDou 1657" (GD in ligature). The Leiden Collection, New York, GD-108 (b) verso
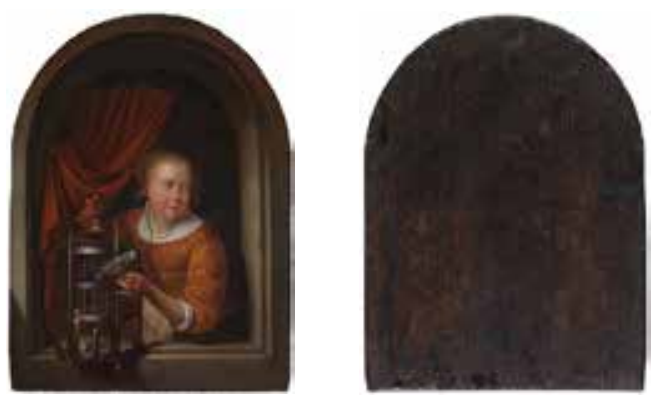

Fig. 9a Gerrit Dou, Young Woman Holding a Parrot, ca. 1660-65, oil on panel, $24.8 \times 18.6 \mathrm{~cm}$. The Leiden Collection, New York, GD-105 (b) verso
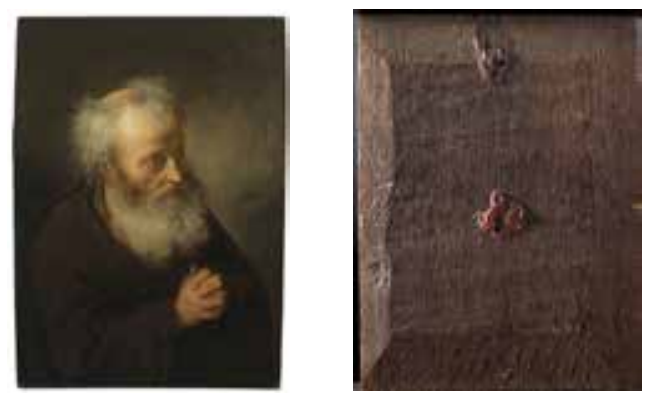

Fig. 11a Gerrit Dou, Hermit Praying, ca. 1665-70, oil on panel, 18 $\times 12.9 \mathrm{~cm}$, signed, center right, " $G D$ "(GD in ligature). The Leiden Collection, New York,GD-107
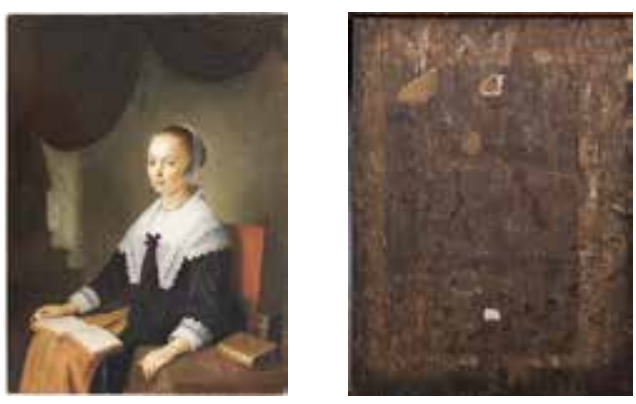

Figs. 6a-b (a) Gerrit Dou, Portrait of a Lady with a Music Book, ca. 1640-44, oil on panel, $27.1 \times 19.8 \mathrm{~cm}$, signed, on the book, "GDou" (GD in ligature). The Leiden Collection, New York, GD-116 (b) verso
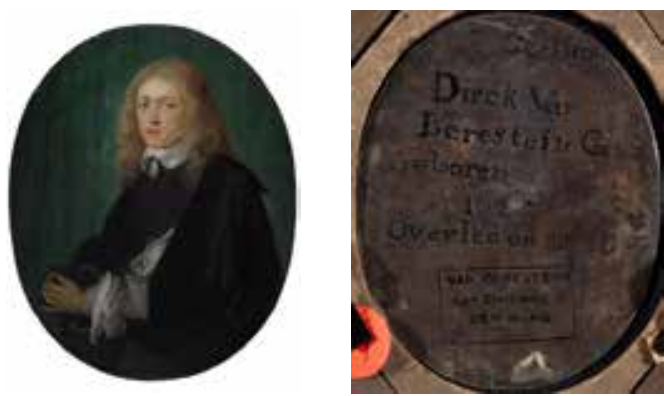

Fig. 8a Gerrit Dou, Portrait of Dirck van Beresteyn, ca. 1652, oil on silver-copper alloy support, oval, $10 \times 8 \mathrm{~cm}$, signed, upper right, "GDou" (GD in ligature). The Leiden Collection, New York, GD-111 (b) verso
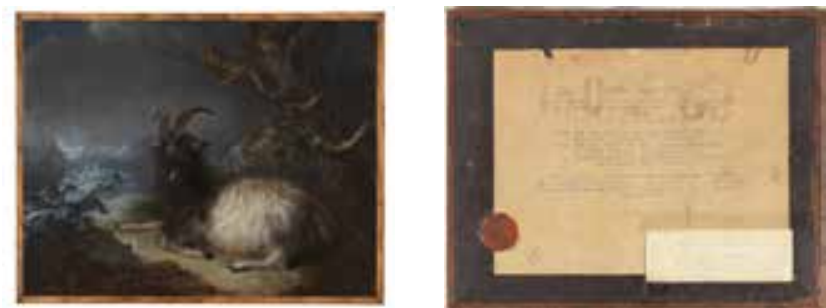

Figs. 10a-b (a) Gerrit Dou, Goat in a Landscape, ca. 1660-65, oil on panel, $19.5 \times 24.9 \mathrm{~cm}$, signed, lower center, "GDou" (GD in ligature). The Leiden Collection, New York, GD-114 (b) verso
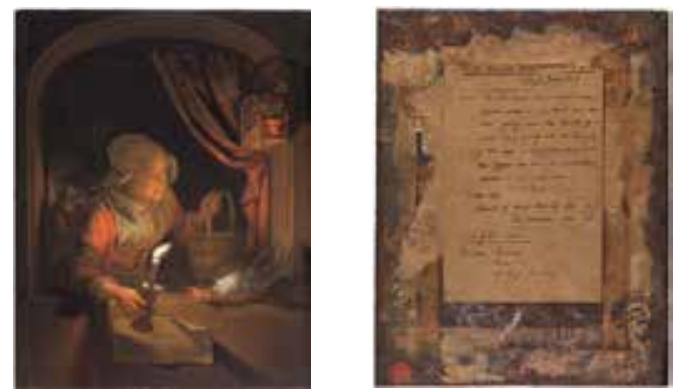

Figs. 12a-b (a) Gerrit Dou,Old Woman at a Niche by Candlelight, 1671, oil on panel, $26.7 \times 20.8 \mathrm{~cm}$, signed, bottom center, "GDovAnno 1671" (GD in ligature). The Leiden Collection, New York, GD-103 (b) verso 

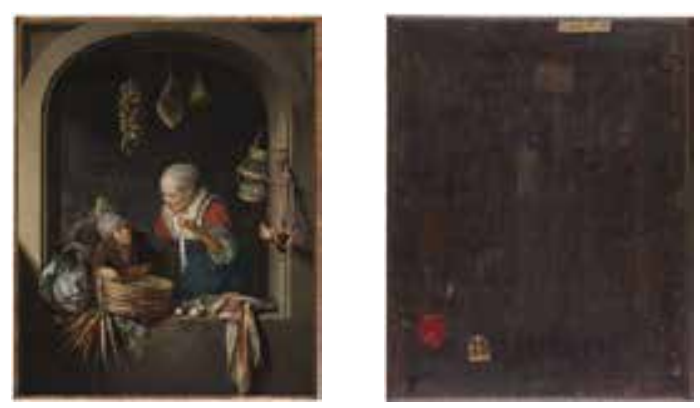

Fig. 13a Gerrit Dou, Herring Seller and a Boy, ca. 1664, oil on panel, $42.3 \times 33.3 \mathrm{~cm}$, signed, bottom center, "GDou" (GD in ligature). The Leiden Collection, New York, GD-106 (b) verso

Gerrit Dou (1613-1675), one of the most important seventeenth-century Leiden artists and progenitor of the so-called fijnschilder style, has received considerable attention in the art historical literature since his rediscovery from relative obscurity in the 1960s. However, only a handful of publications discuss the technical aspects of his work and his work method. ${ }^{1}$ In 1987, Luuk Struick van der Loeff and Karin Groen published their technical research of Dou's 1658 Young Mother in the Mauritshuis, no doubt one of the masterpieces of Leiden fine painting. ${ }^{2}$ One of their conclusions was that Dou adjusted the composition by making several changes over a longer period of time, possibly even five years after having started the painting. ${ }^{3}$ Through microscopic examination and multiple forms of instrumental analysis, Struick and Groen also concluded that Dou achieved the smooth and detailed finish of the Young Mother by applying the finely ground paint in many thin, superimposed layers. This method differed greatly from that of his former teacher Rembrandt, with whom he studied in Leiden between 1628 and ca. 1632. ${ }^{4}$ Their analyses confirmed, for the first time, Dou's use of bitumen and its subsequent role in crack formation in the dark passages.

Six years later, in 1993, Eric Jan Sluijter placed Dou's paint technique in the context of seventeenth-century art theory and criticism, most notably the 1642 art treatise by Philips Angel. ${ }^{5}$ Sluijter discussed Dou's extraordinary manner of balancing highly detailed and meticulous renditions with a loose and free handling of the brush. In particular, Sluijter noted Dou's way of creating a sense of liveliness in an otherwise smooth, enamel-like surface, by applying tiny, parallel brushstrokes, almost like hatchings. ${ }^{6}$ Friso Lammertse, in 1997, discussed the material aspects of Dou's 1652 Quack in Rotterdam and his 1663 Self-Portrait in Kansas City, convincingly demonstrating that there were also considerable changes in these paintings, some of which Dou made years after the paintings had initially been completed. ${ }^{7}$

On the occasion of the Dou exhibition of 2000-2001, Annetje Boersma revisited the Mauritshuis Young Mother and also published findings on Dou's 1667 Lady at Her Toilet in Rotterdam. ${ }^{8}$ Boersma reiterated that Dou generated various changes during the paint process of both paintings and that he superimposed multiple thin paint layers. She also mentioned that some of the pigments, especially in the Young Mother, had changed over time, thus providing us with a slightly different image of the paintings than Dou had intended. ${ }^{9}$ In 2002, Jørgen Wadum published an important article in which he analyzed some of the main characteristics of Dou's paint technique. ${ }^{10}$ He noted the interesting contrast between the high level of finish in Dou's paintings 
and the large number of changes made during the paint process, concluding that under the smooth upper layers, Dou's work method, with the numerous changes and broad brushwork, was more Rembrandtesque than we realize.

Thirteen paintings by Dou in the Leiden Collection in New York constitute the largest group of works by the artist in a private collection, and span the full breadth of his career. ${ }^{11}$ Between 2009 and 2013, the entire group was subjected to technical examination, including three additional paintings, one an early workshop painting attributed to the artist and two considered to be from Dou's circle. ${ }^{12}$ The methods of examination include X-radiography, infrared reflectography, microscopic examination of the paint applications, compositional and stratigraphic analysis of selective pigment samples, and, where possible, dendrochronology. ${ }^{13}$ The goal of this investigation was to broaden our understanding of the artist by building upon the knowledge gained from the studies mentioned above, expanding upon what has been learned by others about the artist's working methods.

This essay represents a progress report highlighting the most significant findings of the research thus far. It is centered on the group of securely attributed paintings by Dou in the Leiden Collection that were examined during the course of the study: Scholar Sharpening a Quill of ca. 1630-35 (figs. 1a-b), Scholar Interrupted at His Writing of ca. 1635 (figs. 2a-b), Portrait of a Young Man with a Hat, ca. 1635 (figs. 3a-b), Portrait of a Lady in Profile of ca. 1635-40 (figs. 4a-b), Portrait of a Gentleman with a Walking Stick of ca. 1645 (figs. 5a-b), Portrait of a Lady with a Music Book of ca. 1640-44 (figs. 6a-b), Cat Crouching on the Ledge of an Artist's Atelier, dated 1657 (figs. 7a-b), Portrait of Dirck van Beresteyn of ca. 1652 (figs. 8a-b), Young Woman Holding a Parrot of ca. 1660-65 (figs. 9a-b), Goat in a Landscape of ca. 1660-65 (figs. 10a-b), Hermit Praying of ca. 1665-70 (figs. 11a-b), Old Woman at a Niche by Candlelight, dated 1671 (figs. 12a-b), and Herring Seller and a Boy of ca. 1664 (figs. 13a-b). In the following, we discuss insights into Dou's paint technique and present a reconstruction of Dou's painting methods based on our observations and following the sequence of operations Dou would have followed in his paintings. We start with an overview of Dou's supports, followed by a discussion of his ground layers, preparatory design and underpainting, choice of pigments, handling of the paint, and compositional and iconographic changes.

6 Within this study, special focus is given to the two recurring elements in the Dou technical scholarship so far. Firstly, we have looked specifically at Dou's use of pigments and their discoloration over time for insights into the earlier appearances of the works. Due to the small size of most of the paintings as well as their fully restored states at the time of study, cross sections for stratigraphic analysis were rarely possible in important areas of the compositions. Accordingly, pigment identifications are more numerous from the uppermost layers or more heavily painted areas. Our pigment studies focused particular attention on the artist's choice of blues and yellows, since many of the pigments in these colors are likely to change over time. Our findings corroborate some prior observations while adding new insights into Dou's wide choice of pigments and the optical effects achieved between the multiple translucent paint layers. Secondly, like others, we have observed a high frequency of changes in Dou's paintings in the Leiden Collection. Here, we describe the most significant examples that demonstrate the extent to which Dou, during the very process of painting, would go beyond revisions of a merely compositional nature to explore iconographic elements that were integral to the overall meaning of the work. 
It is important to note that this progress report focuses solely on Dou's technique. Unfortunately it lies beyond the scope of this paper to place Dou in the context of his students and contemporaries, partially because in-depth and systematic technical research has not been carried out on other Leiden fijnschilders. It is our hope that this presentation of the results of our research will provide a basis for future investigation.

\section{The Supports}

With the exception of the Portrait of Dirck van Beresteyn, which was executed on a silver-copper alloy, all the paintings by Gerrit Dou in the Leiden Collection were painted on oak panels, the most common wooden support in the Netherlands in the seventeenth century. This is not surprising, since the Leiden fijnschilders generally executed their small compositions on panel supports -- as opposed to canvas. ${ }^{14}$ Although most of the oak for paintings in the sixteenth and early seventeenth centuries came from the Baltic region, the Baltic wood trade declined in the first half of the seventeenth century. ${ }^{15}$ The repercussions of this decline are reflected by the types of oak panels used by Dou. Most of Dou's earlier works in the Leiden Collection, for instance his Scholar Interrupted at His Writing of ca. 1635 and his Portrait of a Lady with a Music Book of ca. 1640-44, were executed on Baltic oak (figs. 2b and 6b). ${ }^{16}$ His later works, however, were painted on oak from other sources, such as his 1664 Herring Seller and a Boy (fig. 13b), the oak for which originated in the Franco-German region. ${ }^{17}$

Significantly, there are cases in which Dou's later paintings were executed on Baltic oak, wherein the wood itself was old enough to predate the Baltic wood trade decline. A related, important observation that arose from the dendrochronological analysis of the Dou paintings supports one identified by Annetje Boersma in 2000, namely that Dou frequently used panels taken from trees that were felled considerably before the paintings' execution date. ${ }^{18}$ In three of the paintings discussed in this article, Scholar Interrupted at His Writing of ca. 1635 (fig. 2b), the 1657 Cat Crouching on the Ledge of an Artist's Atelier (fig. 7b), and Goat in a Landscape of ca. 1660-65 (fig. $10 \mathrm{~b})$, the youngest measured annual ring of the panel dates to the late sixteenth century. ${ }^{19}$ In his 1657 Cat Crouching on the Ledge of an Artist's Atelier, the youngest annual ring of the panel dates as early as 1580, implying that the panel could have been ready for use as early as ca. 1591-97. Ian Tyers noted that this early dating could suggest prior use of the board, for example, for wood paneling. ${ }^{20}$ For many other panels there is a considerable period of time between the year in which the youngest heartwood ring was formed and the year to which the panel is dated, which again reinforces Boersma’s observation.

10 Regardless of the origin and the age of the wood, all timber went through a long processing period from the moment it arrived in the harbor of Amsterdam to the day Dou was able to paint on it. In Dou's lifetime the wood would probably have been cut and smoothed down in mechanized sawmills. ${ }^{21}$ Only one painting in the Leiden Collection, the Hermit Praying, appears to have been cut by hand, for the intact reverse contains the irregular grooves presumably created by a handsaw (fig. 11b).

11 Dou would not have purchased his ready-made panels from the miller directly but from specialist panel makers. ${ }^{22}$ Panel makers would normally bevel all four edges of the reverses down to a thick- 
12 ness of a few millimeters, most likely to enable a comfortable fitting in their frames. ${ }^{23}$ The Hermit Praying is an example of a panel that retains the original beveling on all four sides (fig. 11b). Sometimes, however, a panel was only beveled on three sides, because one side was naturally thinner due to the way it had been cut radially from the tree trunk, as exemplified in the panel of Herring Sellerand a Boy (fig. 13b). ${ }^{24}$ Unfortunately, none of the Dou panels in the group contain any panel-maker marks, making it impossible to uncover the panel makers that Dou favored. ${ }^{25}$

13 Panels were available to Dou in a range of standard panel sizes, which corresponded with standard frame sizes. ${ }^{26}$ In 1997, Ernst van de Wetering observed that almost all of Rembrandt's Leiden panels, many of which were executed during the time that Dou studied with him, can be arranged according to ten clusters of standard sizes. ${ }^{27}$ In 2001, Christoph Schölzel published a similar list of six standard panel sizes especially encountered among the Leiden fijnschilders, based on the holdings of the Gemäldegalerie in Dresden. ${ }^{28}$ Although the paintings by Dou in the Leiden Collection fit into several of the categories recorded by Schölzel, the majority fall under the first, smallest category, measuring approximately $26 \times 20 \mathrm{~cm}$, including his Scholar Sharpening a Quill, Scholar Interrupted at His Writing, Goat in a Landscape, and Hermit Praying, discussed in this essay. ${ }^{29}$

14 The division of the Leiden Collection panels according to these categories of standardized panel sizes leads to two insights. First, the panel sizes are not restricted to any particular period within Dou's career -- he used different panel sizes throughout his life. The second is that Dou's preferred size, whether by his choice or by that of his patrons, was the smallest, approximately $26 \mathrm{x} 20 \mathrm{~cm}$, which, interestingly, corresponds with Schölzel's findings among the Dou paintings in Dresden. ${ }^{30}$

15 One of Dou's paintings, the Portrait of a Lady in Profile, preserves an unusual format that represents a later configuration. The oval panel with the portrait, measuring $13.3 \times 11.3 \mathrm{~cm}$, was set into a larger, rectangular panel, measuring $18.4 \times 15.3 \mathrm{~cm}$. The reconfiguration of the panel is visible from the front only, so that the panel itself provides a full encasement for the oval board (figs. 4a-b). Traditionally, this painting is placed in Dou's early oeuvre, in ca. 1635-40, which has also more recently been confirmed by historical analysis of the sitter's costume and jewelry. ${ }^{31}$ Dendrochronological analysis of the larger, rectangular panel carried out by Ian Tyers, however, has revealed that its youngest annual ring can be dated to 1653, suggesting that it could not have been ready for use until ca. $1664-70 .^{32}$ It thus seems that the oval portrait was inlaid into the larger panel in the 1660s or 1670s. It is not clear why the painting was adapted to a larger format in this manner, or why this happened approximately two decades after the painting's execution. In Dou's oeuvre there are other examples of panels that were later inserted into larger panels, for instance his ca. 1655 Young Lady on a Balcony in the National Gallery in Prague. ${ }^{33}$

16 The Portrait of Dirck van Beresteyn is painted on a rare type of metallic support, which is, as far as we are aware, unique among Dou's works (fig. 8b).$^{34}$ Paintings that utilize a hammered copper sheet for the support are not unusual in Dutch works of the seventeenth century and span a range of sizes. In some cases the copper has been clad with silver, a step that reduces some forms of adverse interaction between painting and copper support. However, for this portrait Dou used a hammered oval sheet created from an alloy of silver and copper -- a fused mixture of the two metals analogous to sterling or coin silver. The use of this more costly material aligns with Dou's preference for precision and finish and was made less expensive by the tiny size of the painting. ${ }^{35}$ 


\section{Ground Layers}

17 After the panel or metal support was fashioned by a specialized craftsman, Dou would have arranged to have it further prepared for painting by a "primer" (primuerder). In Leiden, Dou probably relied on the local frame-maker Dirck de Lorme, who provided the service of priming panels and canvases for local artists up until his death in 1676, when the work was taken over by Leendert van Nes. ${ }^{36}$ The ground layer was prepared with a mixture of chalk in glue and would have been applied to the support by De Lorme before being brought back to Dou's studio. Its function was to fill in the crevices of the wood grain and smooth out any irregularity in the surface.

18 Until now, our knowledge of Dou's grounds was limited to the study of two mid-career paintings: The Young Mother from 1658 in the Mauritshuis and the Lady at Her Toilet from 1667 in the Boijmans Van Beunigen Museum. ${ }^{37}$ In both cases, the light-colored ground was found to be very thin. Struik van der Loeff and Groen noted in particular that the ground application of The Young Mother was prevalent in the crevices of the wood grain and inconsistently thick from place to place. In some samples of cross sections taken, the ground was entirely absent, while in other areas, they noted a much thicker chalk ground..$^{38}$ Our own direct observations confirm that the ground tends to be highly variable among Dou's paintings, although the irregularity of the ground structure in Scholar Interrupted at His Writing is similar to that of The Young Mother, despite the fact that more than two decades separate them. ${ }^{39}$ Little is known about the grounds of a wider group of paintings in Leiden during this period, yet one would expect to find the ground composition and its variability to be a widespread occurrence rather than a representative trait unique to Dou.

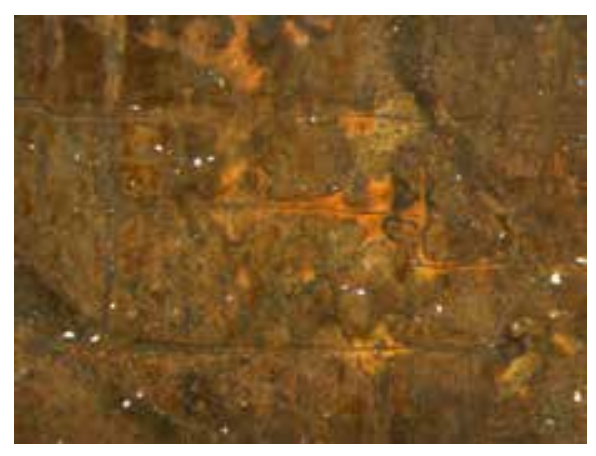

Fig. 14 Detail of the cloak of the scholar's proper right shoulder of Scholar Interrupted at His Writing showing losses that reveal a rust-colored sketch over a light-colored ground and primuersel, field of view: $2.75 \mathrm{~mm}$ (photomicrograph: John Twilley)

19 The upper ground, or first layer of color applied on top of the ground, is what Karel van Mander called the primuersel, or priming, sometimes known by the Italian imprimatura. ${ }^{40}$ This thin, translucent layer, generally made up of a mixture of chalk, lead white, and earth pigments for toning, is oil based and covers the entire ground, making the ground layer less absorbent, while providing an intermediate tint to the surface. Wadum described this layer in the Dou paintings he examined as being light or buff colored. ${ }^{41}$ In Scholar Interrupted at His Writing, ca. 1635, the light-colored primuersel is visible through areas of miniscule losses in the scholar's cloak under a rust-colored, monochrome painted sketch (fig. 14). ${ }^{42}$ In a painting from three decades later, Goat in a Landscape, a cross section taken from the sky shows an umber-toned primuersel layer that is relatively thin and located between the ground and the grayish-blue undermodeling (figs. 41ac). ${ }^{43}$ 


\section{Preparatory Design and Underpainting}

20 Because no preparatory drawings by Dou survive, it appears that he did not work out his compositions beforehand on paper. ${ }^{44}$ Dou seems to have sketched his compositions directly onto the panel, or primuersel layer, with line or brushed underdrawings. Wadum listed numerous instances of underdrawings found in Dou's work that he described as essentially "fragmented," yet he reproduced very few examples that give a clear indication of their character and appearance. Wadum suggested that Dou must have laid down detailed compositions directly onto the panel in different levels of detail. ${ }^{45}$

21 We can assume that Dou executed complete compositional sketches in the preparatory design phase, even though only certain linear areas are visible in infrared imaging. Dou does not seem to have consistently used a carbon-pigmented medium, nor do all of his paintings have visible linear underdrawings. ${ }^{46}$ Variations in sketch work may be explained by the use of different pigments and different brushes used in the same painting. This variability extends beyond the choice of materials to the character of the sketch itself. While Dou seems to have treated certain areas with careful linear precision, particularly areas of the face, hands, and occasionally outlines of books and other still- life objects, he probably sketched out other areas using different pigment. ${ }^{47}$ In these areas, we usually see a complex matrix of washy brushstrokes that appear very spontaneous in character. It is possible that this dynamic sketch work overlays, and obscures, more preliminary line drawings, but it is also possible that the brushy sketch work visible in the infrared image constitutes Dou's initial inlay of the design.

22 Four paintings in the Leiden Collection contain faint traces of Dou's line underdrawings, each located in isolated areas. ${ }^{48}$ In Scholar Sharpening a Quill from ca. 1630-35, there are several thin, yet distinct, contour lines visible around the upper page of the book and on the top ridge of the hourglass (fig. 15). Similarly, a fine sketch in the birdcage hanging on the wall in the background of Scholar Interrupted at His Writing is partially visible in the infrared image, as is the broadly sketched silhouette of the oblong object that represents an earlier compositional idea (fig. 16). In this same painting, faint lines visible through the paint of the scholar's ear coincide with those

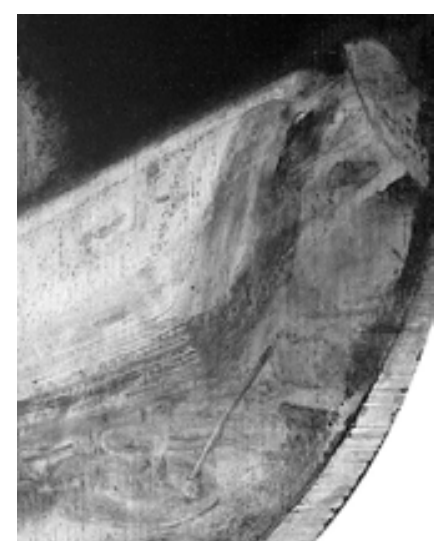

Fig. 15 Infrared image detail of Scholar Sharpening a Quill showing line underdrawings of the book and hourglass, together with a broader-brushed sketch at the top rim of the book. InGaAs camera using1500-1680nm filter (image: Shawn Digney-Peer)

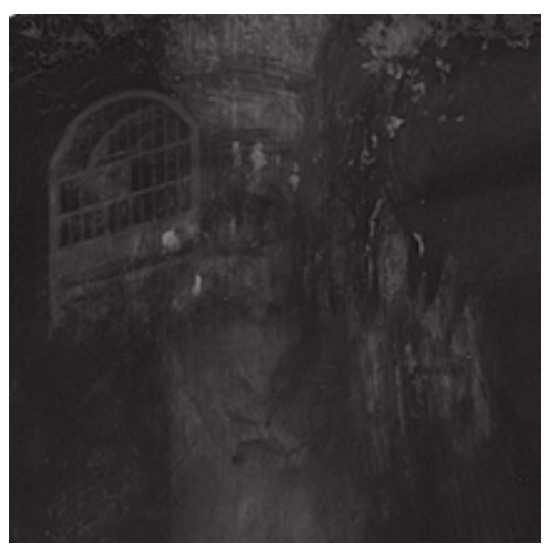

Fig. 16 Infrared image detail of Scholar Interrupted at His Writing showing underdrawing and modeling around birdcage at the upper center. InGaAs camera using 1500-1680nm filter (image: Shawn Digney-Peer) 


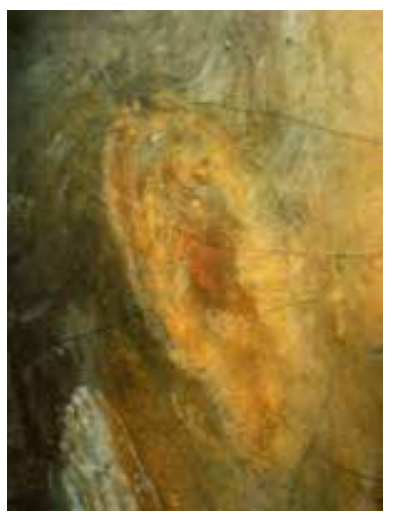

Fig. 17a Detail of Scholar Interrupted at His Writing showing visual detail of ear with faint sketch lines, field of view: $11 \mathrm{~mm}$

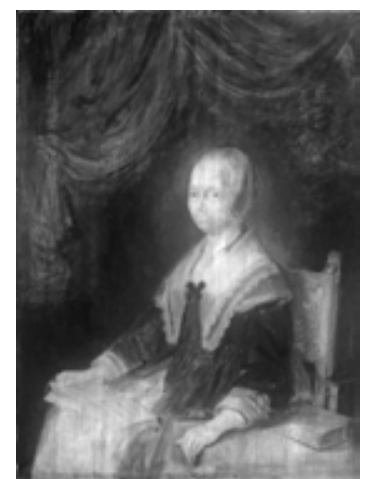

Fig. 18 Infrared image of Portrait of a Lady with a Music Book showing delicate line drawing around the books, as well as vigorous undermodeling of the woman's outer gown, in the dead coloring phase. InGaAs camera using1500-1680nm filter (image: Shawn Digney-Peer)

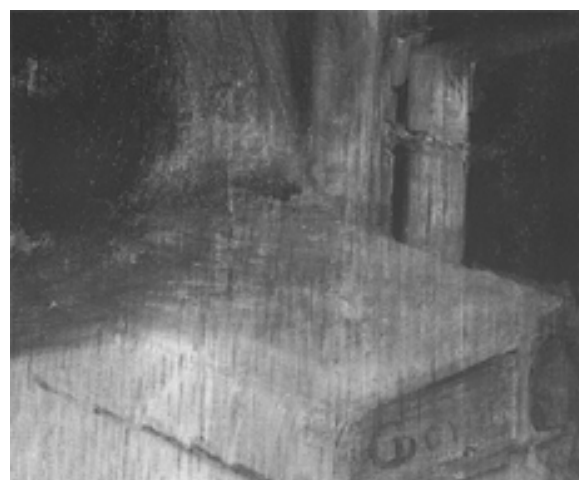

Fig. 20 Infrared image detail of Portrait of a Lady with a Music Book showing the line underdrawings of the books on the table at the far right. InGaAs camera using1500-1680nm filter (image: Shawn Digney-Peer)

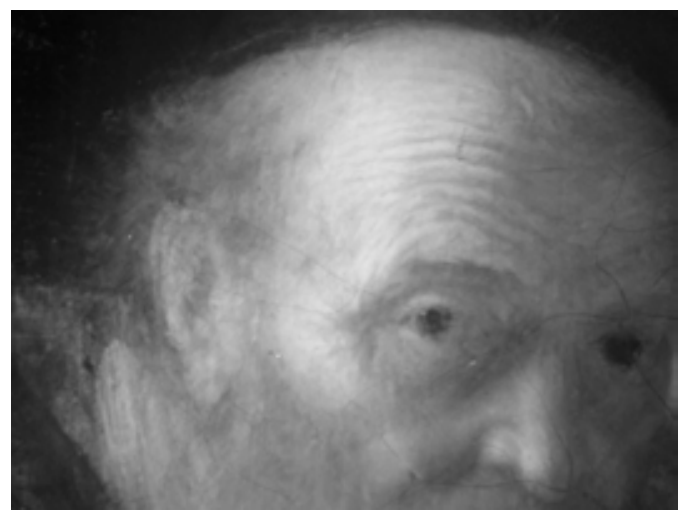

Fig. 17b Infrared image detail of the face, 875-1100nm filter (photomicrographs: John Twilley)

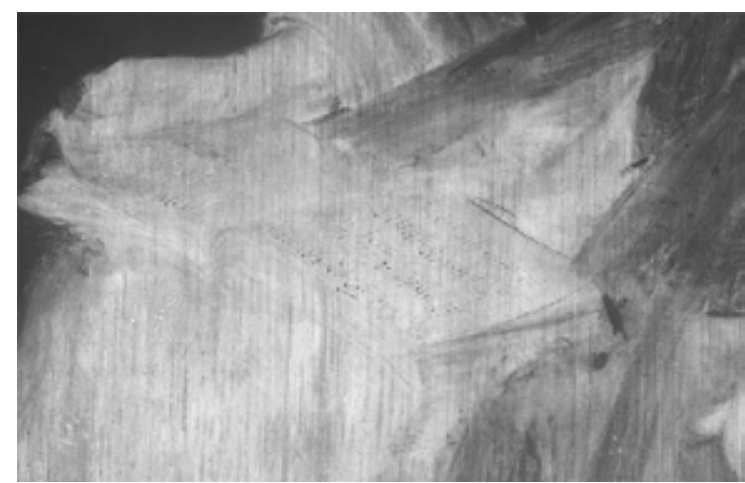

Fig. 19 Infrared image detail of Portrait of a Lady with a Music Book showing the line underdrawing of the book on the woman's lap. InGaAs camera using1500-1680nm filter (image: Shawn Digney-Peer)

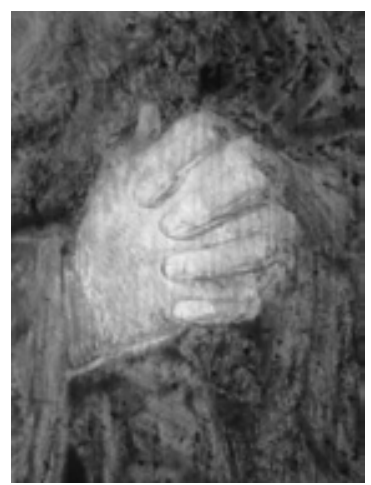

Fig. 21 Infrared image detail of Hermit Praying showing underdrawing of the hands, 800-900nm filter (photograph: John Twilley)

seen in the infrared (figs. 17a-b). In Portrait of a Lady with a Music Book from about 1640-44 (fig. 18) a number of fine lines define the pages of the book on the woman's lap (fig. 19), as well as the books located on the table at the far right (fig. 20). A later example dated to the second half of the 1660s, Hermit Praying, contains a finely delineated underdrawing in the hermit's hands, especially in the joints of the folded fingers and fingernails (fig. 21). ${ }^{49}$ 
23 Dou executed broad sketching for most of the compositional elements, including the areas of fabric and dress. In Hermit Praying, one can see much more freely brushed sketch work in the folds of the cloak, particularly in the garment crease of the figure's proper left arm (fig. 22). This type of broad treatment is seen in Portrait of a Gentleman with a Walking Stick from the early 1640s, in which Dou loosely sketches a more elaborate architectural setting, including an arched doorway in the center of the composition as well as a column and base at the far left, both of which were later omitted in the final composition (figs. 23a-b). A preliminary, broad-line sketch in the same painting, found below the figure's proper right collar, may have originally indicated the lapel of his cape (figs. 24a-b).

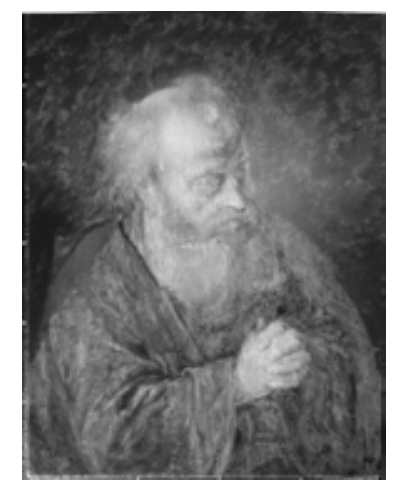

Fig. 22 Infrared image of Hermit Praying showing vigorous undermodeling in the cloak and changes along both shoulders, 950-1000nm filter (image: John Twilley)
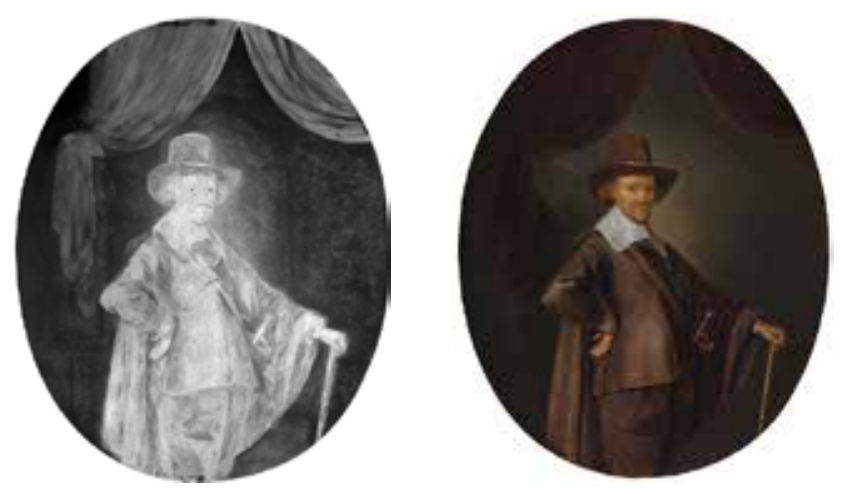

Fig. 23a Infrared image of Portrait of a Gentleman with a Walking Stick showing initial sketch of arched doorway in the background and column with base on the left. InGaAs camera using 1500-1680nm filter (image: Shawn Digney-Peer) Fig.23b Visible image
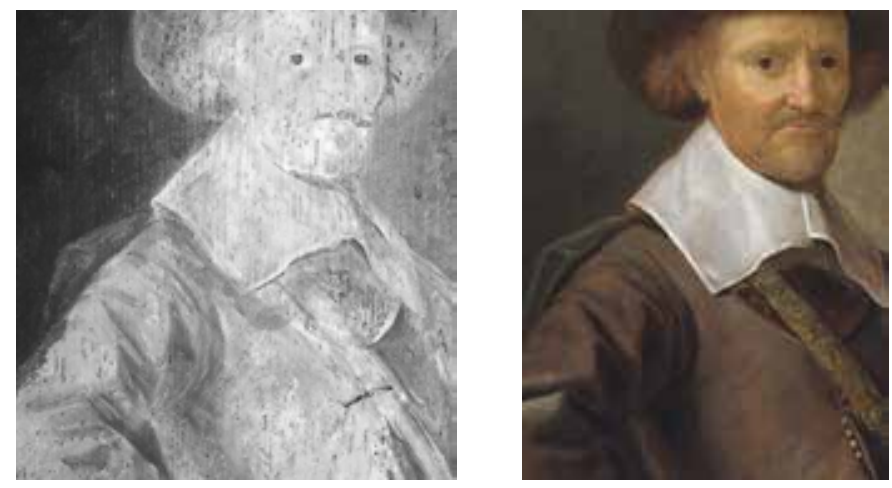

Fig. 24a Infrared image detail of Portrait of a Gentleman with a Walking Stick showing changes in the collar, lapel, or breastplate during the preparatory stage, 1000-1050nm filter (image: Annette Rupprecht)

24 This broad sketching appears to have been laid down after the more careful linear drawing. In Portrait of a Lady with a Music Book, the sketch of the woman's black outer gown overlaps the corner of the finely -- and previously -- delineated book on her lap (fig. 19). Similarly, in Scholar Sharpening a Quill, we can see a single bold brushstroke in dark pigment that appears to be a subsequent reinforcement of the rim of the top of the book, adjacent its linear drawing (fig. 15). Yet, other brushwork, due to its free execution style and spontaneous character, suggests an exploratory phase of the design, as seen in Scholar Interrupted at His Writing. There, thick and 
cursory brush strokes in darker pigment are visible in the infrared image along the garments of the scholar's proper right arm (fig. 25). Other freely and broadly painted strokes seen at the edge of the table suggest that Dou may have originally conceived of the table as round rather than rectangular.

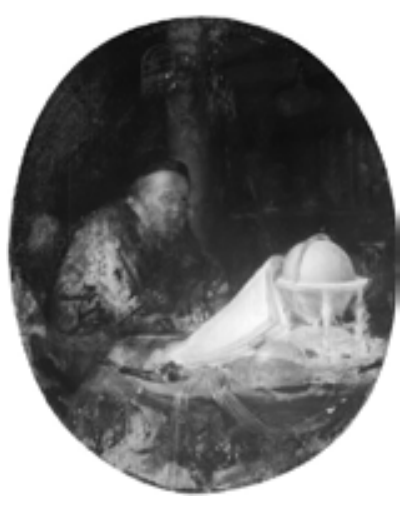

Fig. 25 Infrared image of Scholar Interrupted at His Writing showing broad brushwork in the scholar's garment and along the front of the table. InGaAs camera using 1500-1680nm filter (image: Shawn Digney-Peer)

It is clear, however, that at times the sketch work was executed in place of careful line drawings. In Scholar Sharpening a Quill, much of this early phase brushwork is visible in the infrared image (fig. 26). The scarf tied around the scholar's neck appears in the preliminary sketch as a simpler tie (figs. 27a-b), while his proper right cuff was sketched in broader strokes with darker pigment, suggesting that Dou initially had in mind a heavier or different fabric from what he painted in the final version. In this preliminary stage of the composition, it is evident that the loosely executed brushwork begins to give volume to form by indicating the play of light and shadow.

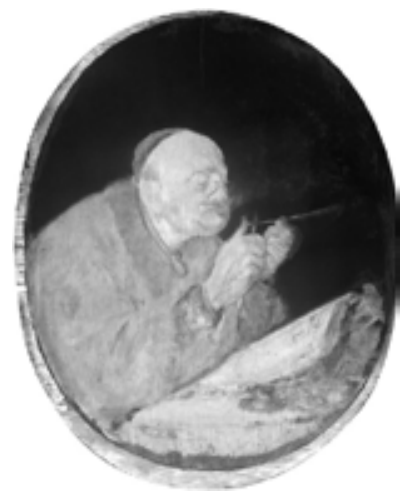

Fig. 26 Infrared image of Scholar Sharpening a Quill showing brushed sketch work of scarf around scholar's neck and original position of the inkwell. InGaAs camera using 1500-1680nm filter (image: Shawn Digney-Peer)
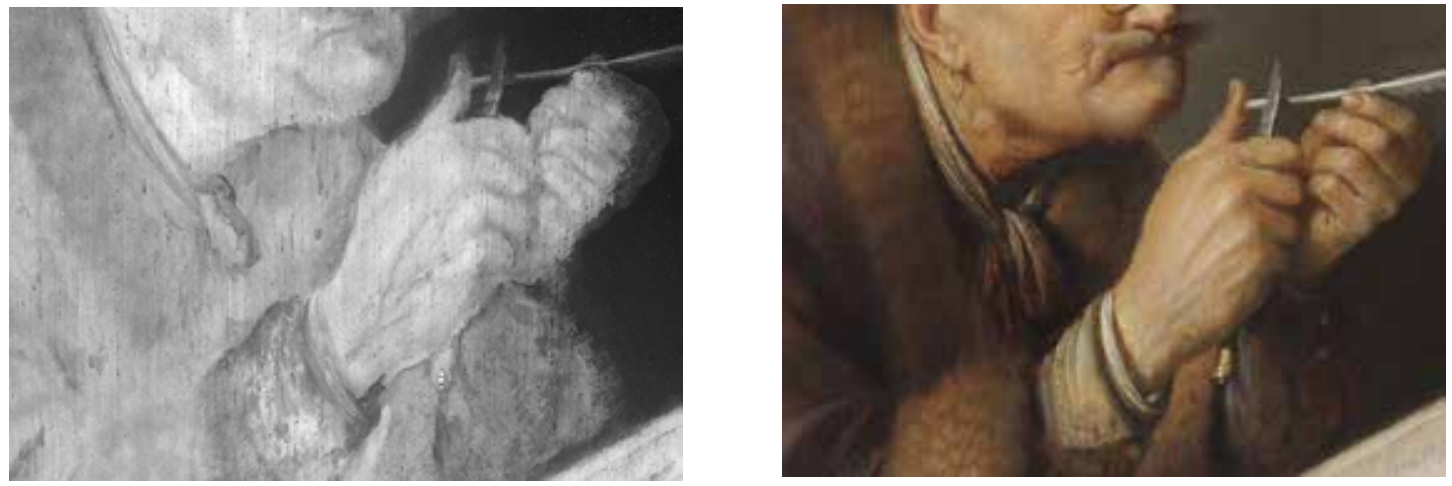

Fig. 27a Infrared image detail of Scholar Sharpening a Quill showing the brushsketch in the scarf around the scholar's neck and the dead coloring around the figure's proper left hand knuckles. InGaAs camera using1500-1680nm filter (image: Shawn Digney-Peer). Fig. 27b Visible image 
After the "invention" phase of the composition, the second stage involved the execution of the first paint layer in muted colors, sometimes referred to as "dead coloring." 50 The purpose of the dead coloring phase was to begin to give volume and body to form while differentiating the various planes and outlining silhouettes in various tones of paint that would later be built up with color. Like his teacher Rembrandt, who sometimes executed his initial sketch directly on the ground with a broad brush while laying in the first tonal color, we can assume that Dou, under his tutelage, would have learned to do the same in the early stages of the composition. ${ }^{51}$ Wadum, in fact, characterized this stage in Dou's painting as one of "vigorous undermodeling." 52

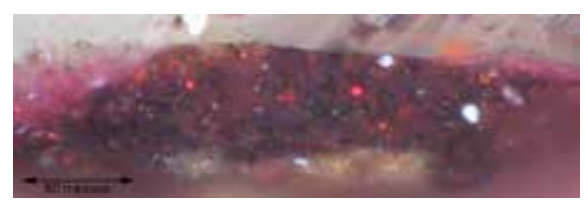

Figs. 28a-c Sample from the cloak of Scholar Sharpening a Quill showing the violet-brown dead color and upper violet lake layer a) Cross section in reflected light (the top layer is retained only at the left end), 200x b) UV autofluorescence differentiating the two layers, 200x c) Partially dispersed pigments from both layers showing particles of lake from the top layer and iron earth pigment with Kassel earth from the dead coloring, transmitted light with partially crossed polars, 400x (photomicrographs: John Twilley)

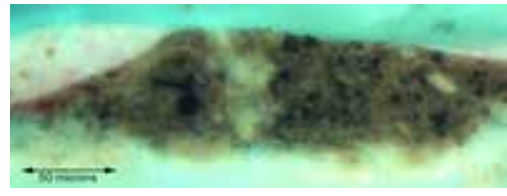

Figs. 28a-c Sample from the cloak of Scholar Sharpening a Quill showing the violet-brown dead color and upper violet lake layer a) Cross section in reflected light (the top layer is retained only at the left end), 200x b) UV autofluorescence differentiating the two layers, 200x c) Partially dispersed pigments from both layers showing particles of lake from the top layer and iron earth pigment with Kassel earth from the dead coloring, transmitted light with partially crossed polars, $400 x$ (photomicrographs: John Twilley)

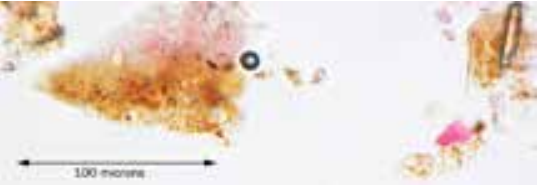

Figs. 28a-c Sample from the cloak of Scholar Sharpening a Quill showing the violet-brown dead color and upper violet lake layer a) Cross section in reflected light (the top layer is retained only at the left end), 200x b) UV autofluorescence differentiating the two layers, 200x c) Partially dispersed pigments from both layers showing particles of lake from the top layer and iron earth pigment with Kassel earth from the dead coloring, transmitted light with partially crossed polars, 400x (photomicrographs: John Twilley)

The brushwork visible in the infrared image of Portrait of a Lady with a Music Book, exemplifies the extent of Dou's handling of the dead coloring, ranging from smooth and uniform to sketchy and energetic (fig. 18). The area of the woman's outer black dress, appears as vigorously modeled in rich pigments, while the area surrounding and defining the woman's head, which was left unpainted in reserve, is more uniform. In the area of the figure's garment in Scholar Sharpening a Quill, the dead coloring is a highly saturated, brown-violet mixture, composed mostly of a red lake pigment, iron earth, charcoal, and Kassel earth and smoothly applied (figs. 28a-c). ${ }^{53}$ In the infrared, we see that Dou has distributed a layer across the figure's entire vestment, outlining the overall silhouette with paint. Dou sketched in the figure's cuff and fur collar as tonally distinct, indicating that the opacity and depth of pigmentation would vary from place to place (fig. 26). The infrared also shows that Dou painted the dead coloring of the background around the entire silhouette of the figure, extending around the book and hourglass. Some of this darker layer of the background remains visible through the upper layers of the old man's proper left-hand knuckles, where Dou later revised the position of his hand to the right (figs. 27a-b).

Oftentimes, the dead coloring layer made use of less costly pigments, since its function was to establish a general underlying hue and degree of reflectivity that the upper, translucent paint layers would build upon. A cross section taken from the sky of Goat in a Landscape reveals that the dead coloring forms an intermediary layer of blue-gray that the upper, more costly ultramarine layer very thinly covers (figs. $41 \mathrm{a}-\mathrm{b}$ ). ${ }^{54}$ In a stripped-state photo of the painting taken during conservation treatment, some of this gray undermodeling in the sky was visible in striations along 
the wood grain before retouching (fig. 40).

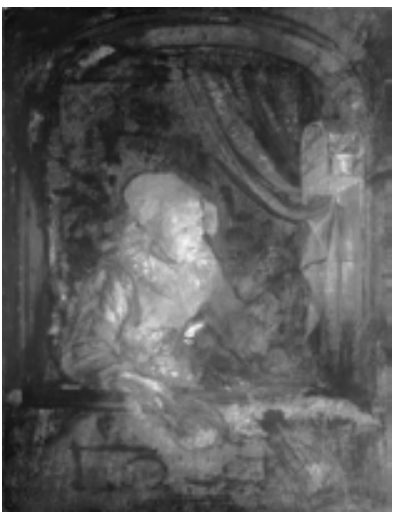

Fig. 29 Infrared image of Old Woman at a Niche by Candlelight showing broadly brushed sketch work in the initial design phase. InGaAs camera using1500-1680nm filter (image: Shawn Digney-Peer)

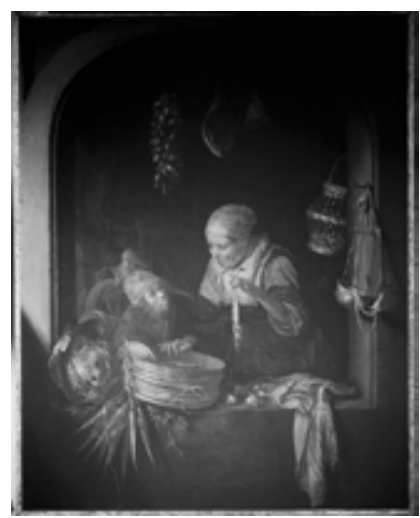

Fig. 30 Infrared image of Herring Seller and a Boy, 1000-1050nm filter (image: Annette Rupprecht)

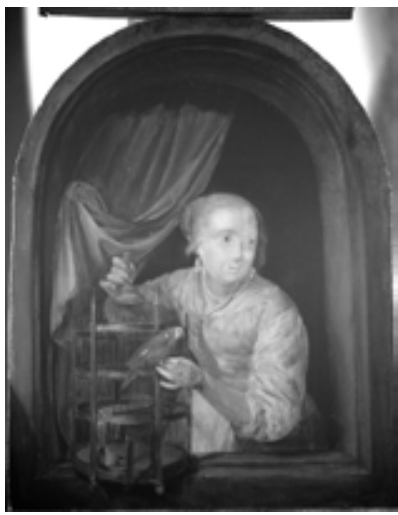

Fig. 31 Infrared image of Young Woman Holding a Parrot, 1000-1050nm filter (image: Annette Rupprecht)

While the opportunity to examine all thirteen paintings in the Leiden Collection using both infrared imaging and X-radiography has provided considerable insight into Dou's underpainting and design phase, it is difficult to determine any clear trends that would allow us to show how Dou's technique evolved over his long career. For example, in comparing the group of four niche paintings that spans his middle to late career, Cat Crouching on the Ledge of an Artist's Atelier, 1657; Young Woman Holding a Parrot, ca. 1660--65; Old Woman at a Niche by Candlelight, 1671, and Herring Seller and a Boy, ca. 1664, we see a variety in the underpainting and the approach to the preparatory sketch. While the Old Woman at a Niche by Candlelight of 1671 appears to have been executed quickly in the initial design phase with much broader, brushy sketch work (fig. 29), neither the Herring Seller and a Boy (fig. 30) nor the Young Woman Holding a Parrot (fig. 31) contain any brushy sketch work in the preliminary phase. They appear to have been carefully planned and straightforwardly executed, without any visible compositional changes during the painting process. The infrared of one final niche scene, Cat Crouching on the Ledge of an Artist's Atelier, provides striking evidence of careful planning and meticulous execution in the early stages of painting, while revealing numerous compositional changes during the painting process that must have occurred over a longer period of time (fig. 71a); these are discussed in greater detail, below.

\section{Selectivity and Precision in Dou's Choice of Pigments}

30 The investigation of Dou's palette in the works in the Leiden Collection was constrained by the small size of most of the paintings and their fully restored states at the time of study. ${ }^{55}$ Dou's choices for blues and yellows have been the subject of particular interest since they offer insight into issues of cost and selection between synthetic and mineral pigments. These colors also offer information about the formulation of violets and greens of which they are often a component. The roles that they play in Dou's sometimes complex, translucent layering are important aspects of the artist's craft that can be fully understood only through their identification. Perhaps most importantly, blues such as smalt, ultramarine, and indigo are frequently affected by fading or color change. The identification of pigment alteration is essential to the recognition of how, and in what 
degree, the paintings differ today from their appearance almost four centuries ago.

31 Among these paintings of the Leiden Collection there is at least one example of every blue pigment known to have been in use during the period, with the exception of blue verditer. The same can be said for Dou's use of inorganic yellows, though the identification of organic colorants in yellow "lake" pigments was not possible, leaving distinctions among organic yellows less clear. ${ }^{56}$ While our study encompasses a significant group of works securely attributed to Dou, it is nevertheless difficult to discern trends in his pigment choices. There are several reasons for this. We have found that even with the number of paintings to which we have access, they are sufficiently varied in the requirements of their diverse subject matter (niche paintings, portraits, genre scenes, interior, exterior, nighttime, and daytime scenes) that it would be extremely speculative to project trends onto this disparate evidence. Directly comparable passages in the paintings are few.

32 At one end of the spectrum of Dou's choice of color, there is an example in the Portrait of Dirck van Beresteyn (fig. 8a) in which a single blue pigment, smalt, is used alone with white, or modified by earth colors and bone black, for all shades of blue in the painting. The condition of the layer is good apart from minute, localized eruptions of lead-fatty acid soaps that are commonly encountered in Dutch seventeenth-century works (fig. 32). ${ }^{57}$ While smalt has been widely observed to undergo a loss of color saturation and graying in the works of many artists, the pigment in this example is in good condition, indicating that the color observed today is not far removed from Dou's original intent (figs. 33 and $34 a-b)^{58}$

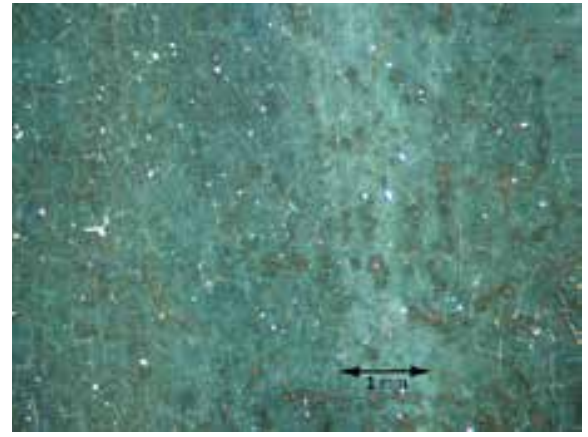

Fig. 32 Detail of Portrait of Dirck van Beresteyn showing the fine craquelure in the blue background near the mid-left edge, field of view: $6 \mathrm{~mm}$ (photomicrograph: John Twilley)

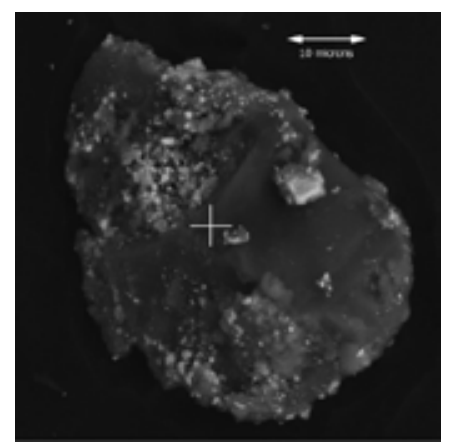

Fig. 34a Smalt grain from the blue background of Portrait of Dirck van Beresteyn (with adhering lead white particles), backscatter electron image, 4,720x (electron micrograph: John Twilley)

JHNA 6:1 (Winter 2014)

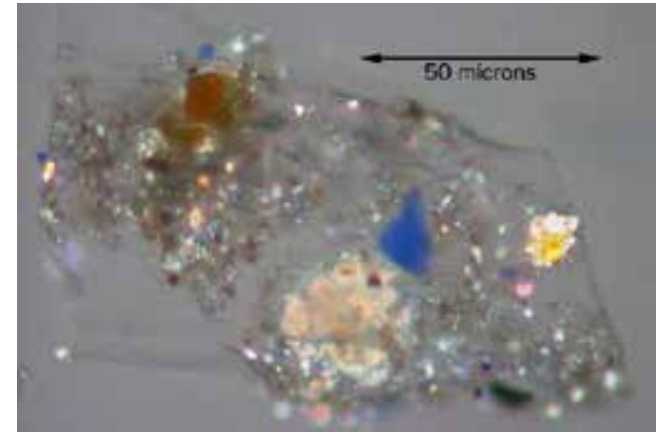

Fig. 33 Dispersed pigments from Portrait of Dirck van Beresteyn showing dark gray paint containing lead white, bone black, well-preserved smalt, and isotropic hydrated iron oxide (goethite), transmitted light with partially crossed polars, 400x (photomicrograph: John Twilley)

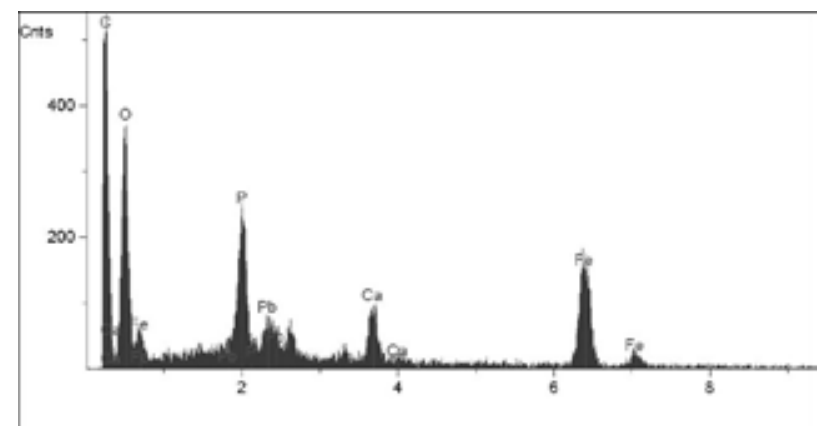

Fig. 34b Elemental composition obtained by X-ray spectrometry during SEM observation. Cobalt in a potash-silica glass is responsible for its blue color. Arsenic detected here is a typical contaminant in cobalt ores used for the coloring of smalt 
33 At the other end of Dou's spectrum, we can observe blues of great complexity in both blending and layering. Testing has revealed that pigment alteration is certain to have impacted the color and interplay of optical effects in some of these constructions. However, the cumulative shift of the observed color is difficult to extrapolate due to the many optical interactions of the multilayered passages. In some cases, the nuances of colors that were originally intended remain very hard to interpret in spite of the detailed knowledge we have obtained about the various pigments and their precise distributions among the layers.

34 Scholar Interrupted at His Writing serves as an example of this complexity by combining the use of the blue pigments vivianite, indigo, and azurite in translucent paint layers (fig. 2a). Dou has made use of the relatively uncommon blue pigment vivianite in the upper layer depicting the shadow of the book where the scarf emerges below it on the table (fig. 35). ${ }^{59}$ Both the tablecloth and the scarf lying on it, which today have an accentuated yellow hue, contain pigment mixtures with large proportions of blue (figs. 36a-c). We can expect that a distinction in color originally

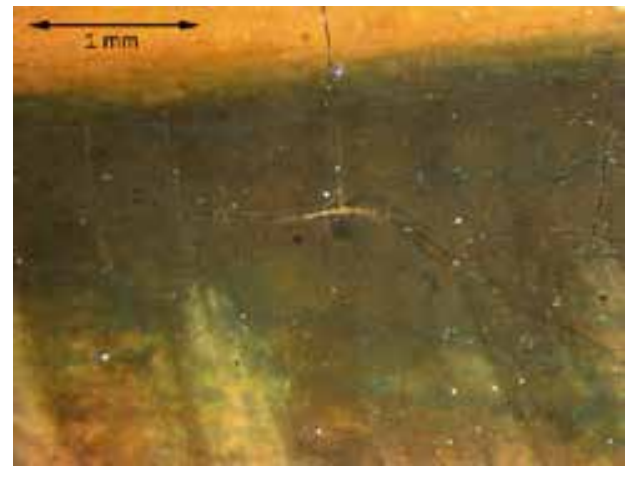

Fig. 35 Detail of Scholar Interrupted at His Writing showing the scarf on the tablecloth emerging from beneath the book where a fine crack disclosed a series of blue layers beneath, field of view: $3.6 \mathrm{~mm}$ (photomicrograph: John Twilley)

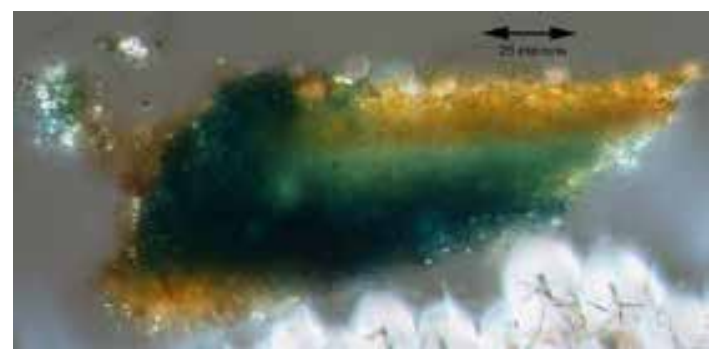

Fig. 36a Thin section from Scholar Interrupted at His Writing, after reduction to 10 microns in thickness, showing the upper layers from the book shadow on the scarf atop the tablecloth, as viewed in transmitted light between crossed polars. The uppermost layer contains vivianite that has transformed from blue to yellow. Indigo masks the bire fringence of azurite and calcite in the intermediate layers, obscuring distinctions among those layers in transmitted light, 500x. (photomicrographs and electron micrograph: John Twilley)

Fig. 36c Backscatter electron micrograph showing the dearth of lead white apart from those areas on the left disturbed by lead soap formations from layers beneath. The uppermost layer contains vivianite that has transformed from blue to yellow. Indigo masks the birefringence of azurite and calcite in the intermediate layers, obscuring distinctions among those layers in transmitted light while they can be differentiated into distinct layers by UV fluorescence microscopy, 500x

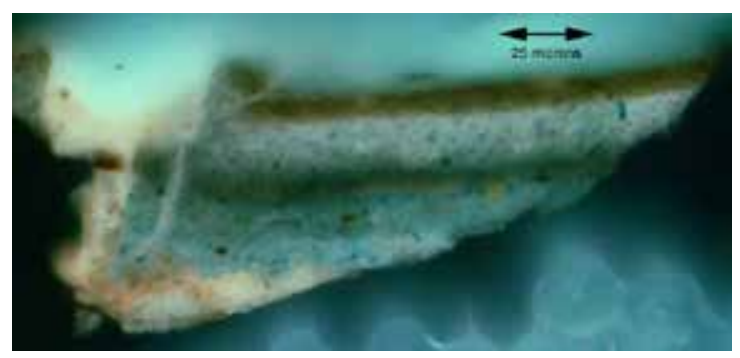

Fig. 36b The section as viewed using ultraviolet fluorescence microscopy by which the intermediate layers can be distinguished on the basis of their autofluorescence, 500x.

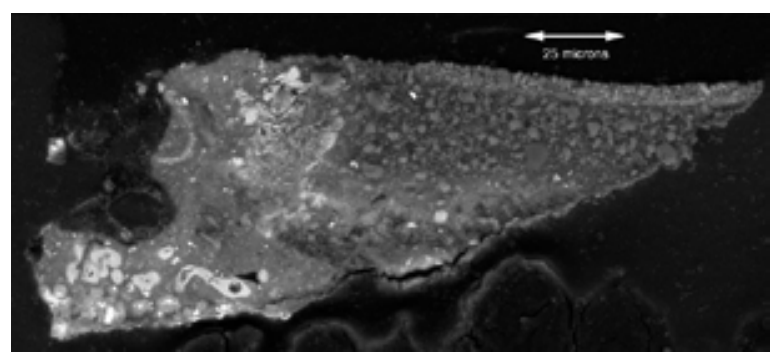


existed between the two cloths. However, since both the azurite used in the tablecloth and the vivianite used in the scarf are brilliant blues, this distinction may have entailed other components, including the influence of underlying colors and the use of glazes that may not have survived cleaning over the centuries. While some degree of yellow in the light reflected from the book onto the scarf below was certainly intended, its intensity has increased due to the yellowing of vivianite in the top layer of the scarf. Based upon its identification by electron microscopy and elemental analysis, the yellowness of the layer, seen in a thin section (fig. 36a), has been confirmed to be due to the alteration of vivianite (figs. 37 and 38a-b) ${ }^{60}$ Calcium carbonate is also present in the top layer and could have served as the base for a yellow lake pigment that would now be difficult to discern in cross section from the discolored vivianite. However, no evidence for the presence of a yellow lake could be found via polarized light microscopy of the dispersed pigment. Likewise, the study of fracture sections in SEM (Scanning Electron Microscopy), in which morphological differences among particles of similar composition are often more readily distinguishable, did not reveal any distinctions between the calcium carbonate of this top layer and that employed in other locations. Therefore, no evidence could be found for the presence of an organic yellow along with the vivianite.

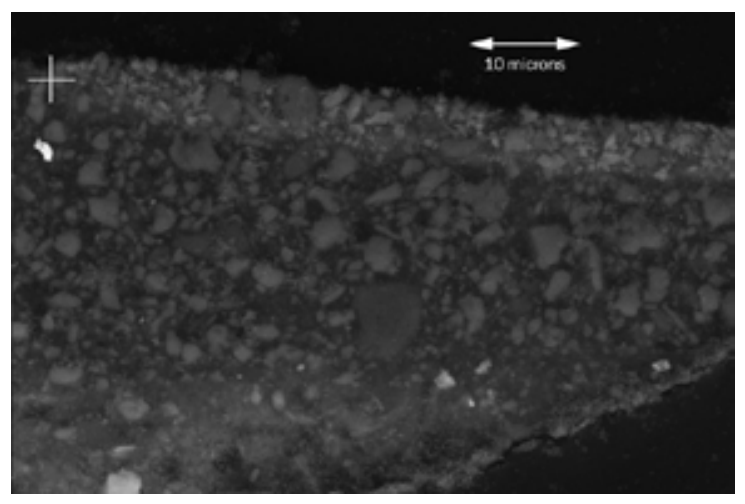

Fig. 37 Cross section detail from the scarf over the tablecloth in Scholar Interrupted at His Writing showing the upper blue strata in the SEM. The low contrast in this backscatter electron image shows the dearth of heavy elements in these layers, including lead white pigment, and implies that they were all intended to be translucent. X-ray spectrometry shows that iron phosphate is common in the top layer (corresponding to the yellow observed in the thin section), and that calcite and gypsum are common in the thicker stratum just beneath. The organic colorant indigo, responsible for blue color in this stratum, is not detectable by this method. Azurite occurs in the lower stratum included in this view, 5,850x (electron micrograph: John Twilley)

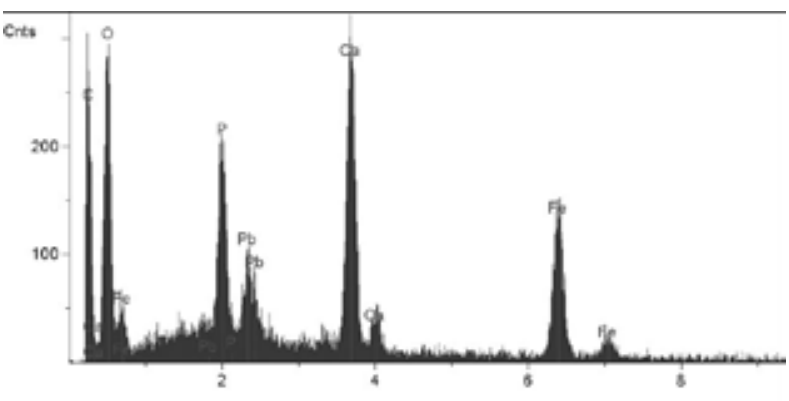

Fig. 38a X-ray spectra from the uppermost yellow layer of the scarf in Scholar Interrupted at His Writing (crosshair in Fig. 37) showing layer composition as a whole, with pigmentation by vivianite and calcite with a near absence of lead white Fig. 38b iron phosphate in individual degraded vivianite particles

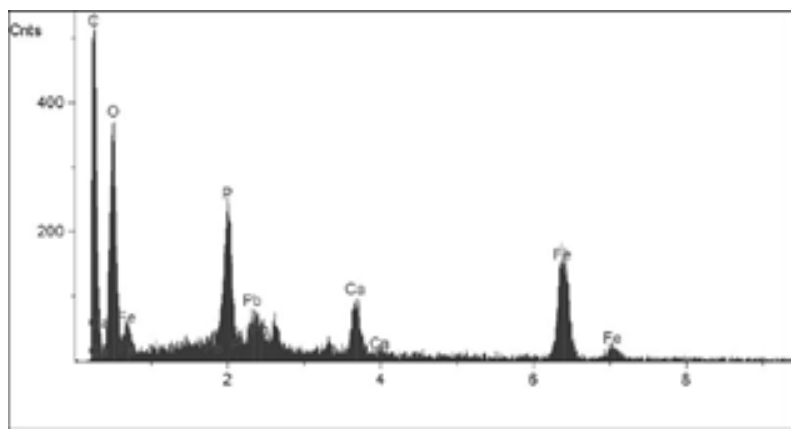

Fig. 38b iron phosphate in individual degraded vivianite particles

35 Another blue pigment, indigo, was used in a lower layer of the tablecloth, which strongly influences the colors of the translucent layers above. Its tendency to obscure the distinctions among the lower layers was mitigated in our tests by the use of ultraviolet fluorescence microscopy (figs. 36a-b) and polarized light microscopy (figs. 39a-b). In addition, the oil medium in all three blues 
can be expected to have undergone its own yellowing. For that reason, the shift toward green is not unique to the discolored vivianite layer and will have impacted the azurite and indigo as well, affecting the appearance of both cloths.

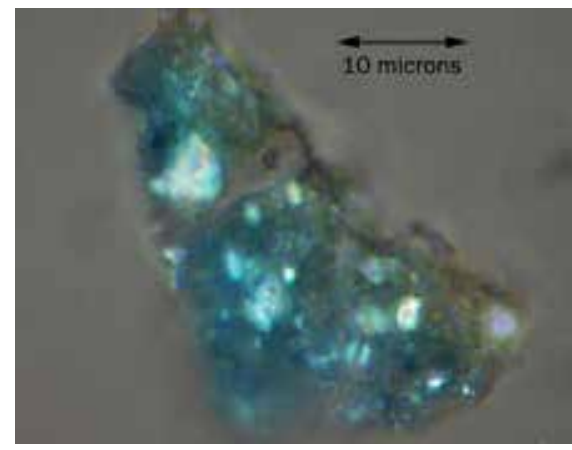

Fig. 39a Partially dispersed pigments from the intermediate layers from the tablecloth and scarf sequence in Scholar Interrupted at His Writing demonstrating the presence of isotropic indigo along with birefringent calcium carbonate. Polarized light microscopy in transmitted light, with polars (photomicrograph: John Twilley)

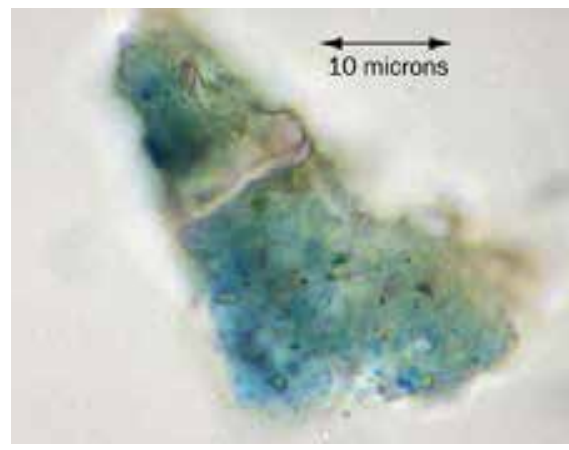

Fig. 39b Without polars, 1,000x

36 Indigo is used here in a mixture that contains calcite and gypsum with virtually no lead white. This ensured that it would be strongly colored but low in reflectivity, thereby contributing to a multilayered sequence in which all strata are translucent. This practice contrasts with the frequently encountered use of an indigo in combination with lead white as a reflective light blue underlayer beneath other blues. Indigo often has its own fading and discoloration problems but, in this case, it is well preserved. ${ }^{61}$ Because of the multiplicity of blue pigments that have undergone various changes in color, as well as the complex optical interactions Dou intended among his superimposed translucent paint applications, it is difficult to interpret how the two cloths in Scholar Interrupted at His Writing would have originally appeared.

37 Goat in a Landscape, an unusual subject for the artist, offers a third example of Dou's use of blue (fig. 10a). All blues in this painting consist of natural ultramarine of very high quality, a costly material relative to alternative blue pigments of the time. ${ }^{62}$ No smalt, indigo, vivianite, azurite, or blue verditer were found, even for the underlayers. ${ }^{63}$ The ultramarine has been employed in different degrees of coarseness and remains vibrantly blue, with no sign of fading or discoloration of the pigment (figs. 41a-c and 42a-b). Gray that is visible in the sky (fig. 40) has been determined

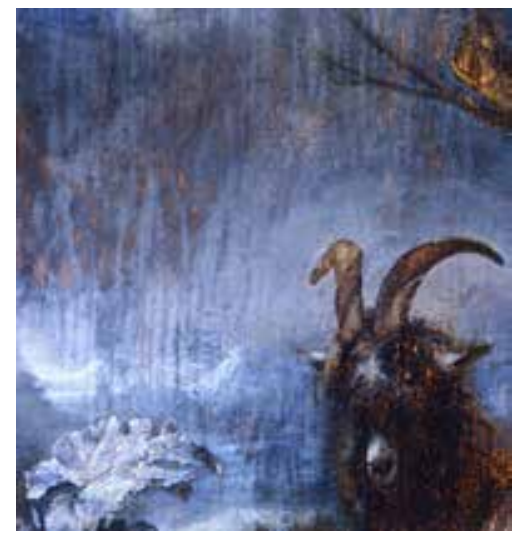

Fig. 40 Detail of a stripped state photo during treatment of Goat in a Landscape showing losses in the sky along striations of the wood grain at the upper left, revealing the gray dead coloring underneath the uppermost layer of ultramarine (photograph: Nancy Krieg) 
through our testing to be due to exposure of an underlayer resulting from wear of the top layer, rather than to discoloration of the blue pigment. A layer of gray-blue beneath the worn top layer of ultramarine in the sky is visible in the cross section, and the ultramarine in both layers remains vibrantly blue (figs. $41 \mathrm{a}-\mathrm{c}$ and 43 ).

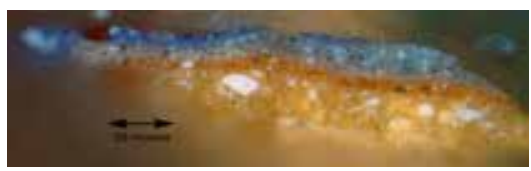

Fig. 41a Cross section of a sample from the sky of Goat in a Landscape showing the ground, primuersel, blue-gray dead coloring, and final blue layers, Cross section in reflected light (photomicrographs: John Twilley)

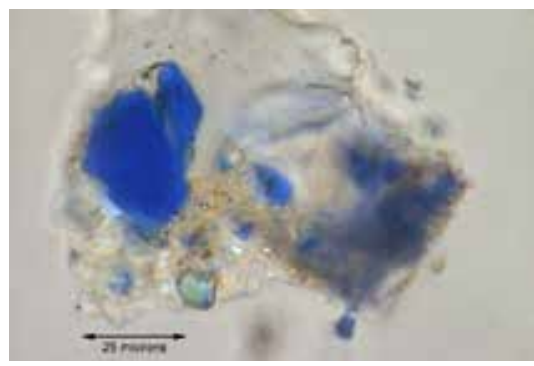

Fig. 42a Dispersed pigments from the sky of Goat in a Landscape showing particles of isotropic natural ultramarine from the uppermost blue stratum that illustrate its great diversity of particle sizes, all in good condition, transmitted light with partially crossed polars, 400x (photomicrographs: John Twilley)

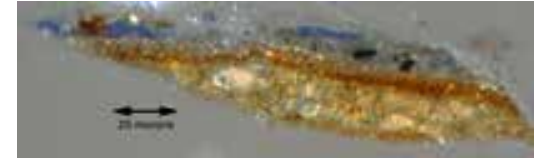

Fig. 41b Thin section in transmitted light with crossed polars

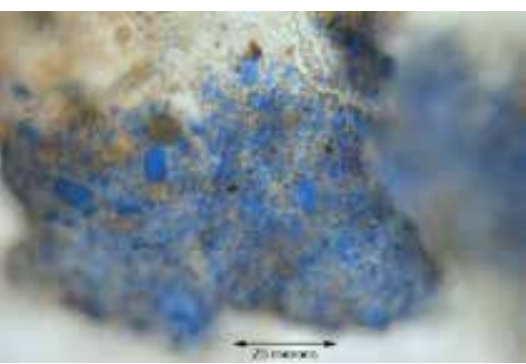

Figs. $42 \mathrm{a}-\mathrm{b}$ Dispersed pigments from the sky of Goat in a Landscape showing particles of isotropic natural ultramarine from the uppermost blue stratum that illustrate its great diversity of particle sizes, all in good condition, transmitted light with partially crossed polars, 400x (both images)

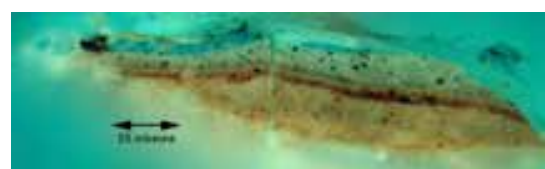

Fig. 41c Ultraviolet autofluorescence showing subdivisions in primuersel, $100 \mathrm{x}$

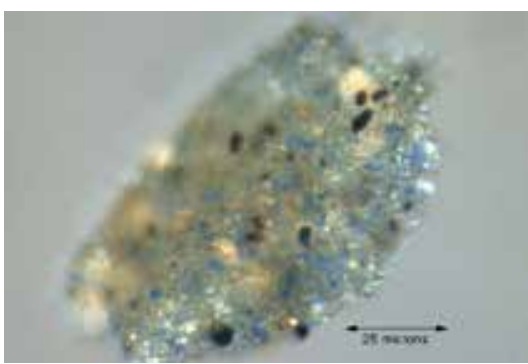

Fig. 43 Partially dispersed pigment from the blue-gray dead coloring of the sky of Goat in a Landscape showing fine ultramarine, lead white and black, demonstrating that this was a purposeful blue-gray mixture and not the result of ultramarine degradation, in transmitted light with crossed polars, 400x (photomicrographs: John Twilley)

The large burdock plant in the lower left corner, which also consists of ultramarine, appears as unusually blue rather than green today, a condition that might be presumed to be the result of the deterioration of a yellow component in the painted structure (fig. 44). However, few remnants of yellow pigment were found in a cross section within the uppermost layer of the foliage. The sample was intentionally taken from a complex, multilayered area and contains a lower, yellow layer that appears unrelated to the final position of the leaf (figs. 45a-d). The blue pigment ultramarine is abundant in the upper, damaged layer, while the much smaller proportion of yellow lake particles is only revealed by fluorescence during UV microscopy (fig. 45c). ${ }^{64}$ The greater concentration of the yellow lake among the more opaque pigments of the lower layers (fig. 45b-c) suggests that these deeper particles could not, by themselves, have reflected sufficient yellow color through the overlying blue to be the sole basis for achieving the green foliage. ${ }^{65}$ This implies that the original green color of the leaves was probably augmented by a final yellow glaze that has not survived. This sample serves as a useful example of the imperative of employing all the methods illustrated in figures $45 \mathrm{a}-\mathrm{d}$, since each reveals an aspect of the stratigraphy or of the pigmentation that is not apparent in the others. 


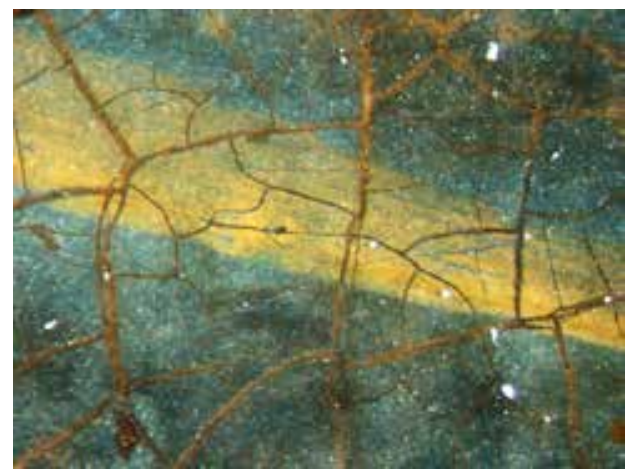

Fig. 44 Detail of a leaf in the foreground of Goat in a Landscape showing deep blue color and the use of yellow ochre for the vein, field of view:

2.75mm (photomicrograph: John Twilley)
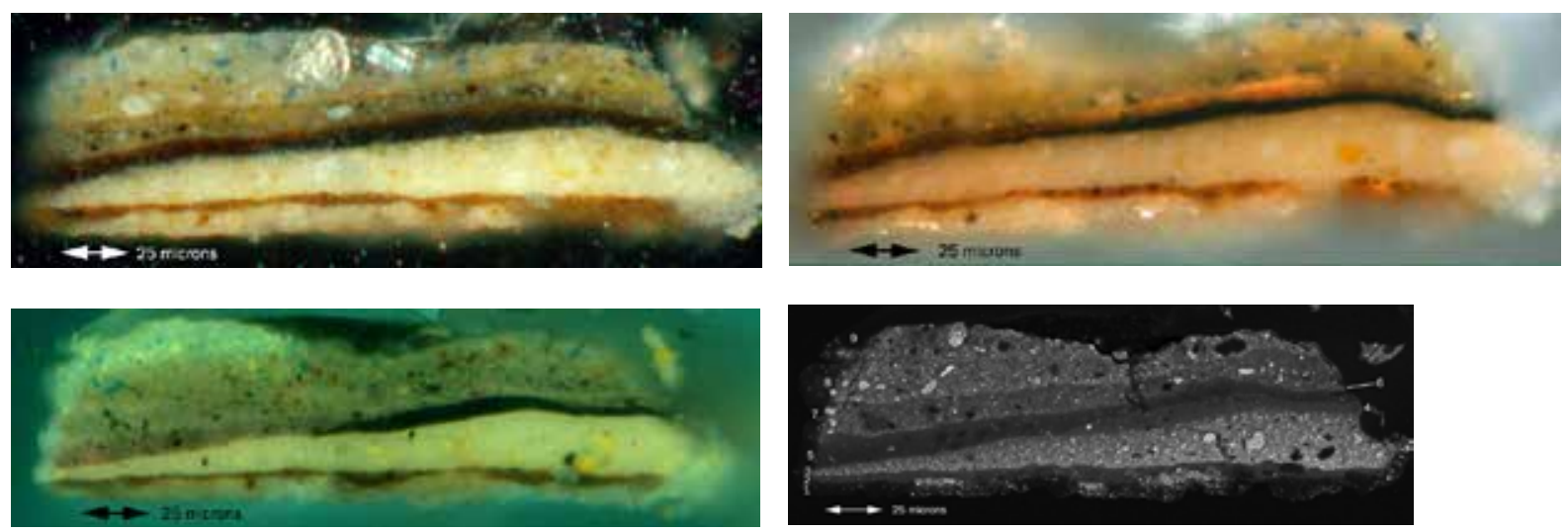

Figs. 45a-d Cross section of a sample from the foreground leaf of Goat in a Landscape showing underlying pale yellow application that has been painted out a) Cross section in darkfield reflected light, 125x b) Thin section in transmitted light with crossed polars, 125x (c) UV autofluorescence showing yellow-fluorescing lakes, including those in opaque lower layers, $125 \mathrm{x}$ d) Backscatter electron image showing additional layer differentiation. At least nine layers are present as noted (photomicrographs and electron micrograph: John Twilley)

\section{The Handling of Paint}

In our discussion of Dou's choice of pigments, we described how Dou's distinctive layering in the Scholar Interrupted at His Writing and Goat in a Landscape contributed to the final blended appearance of color on the surface. Dou used the underlayers in a similar fashion to achieve depth of color and three-dimensionality in the delicate areas of hands and faces. To create half-tones, he underpainted shadows with a dark color over which he applied translucent flesh tones. He used this technique in the face of the old woman in the Herring Seller and a Boy, for example, where he painted pink and paler flesh-tone highlights over a dark-bluish undermodeling along the side of her nose extending down the front of the folds of her cheek to the side of her jaw (fig. 46).

40 In portraying the overlapping of objects in space, Dou followed a logical sequence of building up his compositions by working in sequential planes, from the rear to the front. This order of painting from the background to the foreground must have been one of the methods Dou learned in Rembrandt's workshop, for a number of Rembrandt's early Leiden paintings also follow this order. ${ }^{66}$ In Dou's case, an essential aspect of this practice involved leaving certain foreground elements unpainted in reserve by outlining their silhouette with the adjacent paint of the background, to be painted in at a later stage. ${ }^{67}$ An example from Dou's later career, Young Woman Holding a Parrot from the early 1660s, demonstrates this order in the visually complex area of the birdcage, where several planes of depth overlap to be seen through the front and rear spokes of 
the cage (fig. 47). From microscopic examination of the paint layers, it is clear that Dou built up the composition from the rear wall to the front of the cage. The overlapping paint layers correspond with the building up of the composition, as though moving from the background toward the foreground in space. ${ }^{68}$

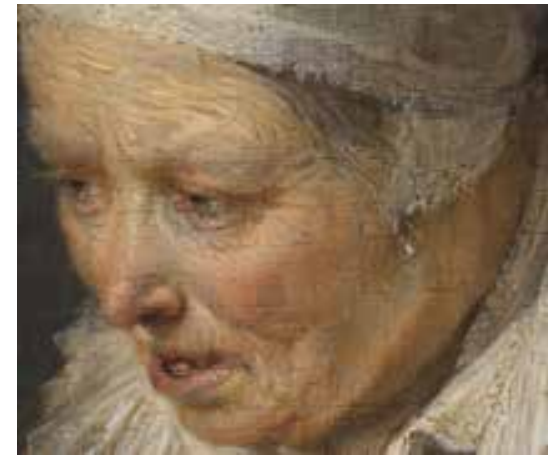

Fig. 46 Detail of Herring Seller and a Boy showing mid-tones in the face of the old woman achieved by dark undermodeling, superimposed with translucent flesh tones and additional highlights

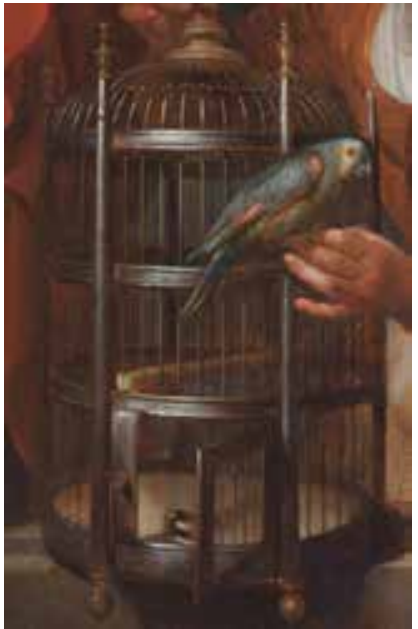

Fig. 47 Detail of Young Woman Holding a Parrot showing the birdcage, an area that represents Dou's working method of painting in sequential planes from the rear to the front

41. One of the more characteristic surface features of Dou's painting technique is his hatching brushwork, consisting of tight, parallel lines in the upper layers of paint. Scholars have noted this distinctive brushwork in a wide range of paintings throughout Dou's career. ${ }^{69}$ In Scholar Sharpening a Quill, the hatching is confined to the highlights of the scholar's right hand (fig. 48), while the technique is also seen enlivening the texture of aging skin along the temple and inside rim of the old man's nose in the face of Hermit Praying (figs. 49 and 50). In Young Woman Holding a Parrot this hatching describes the coarse texture of woolen twill in the curtain (fig. 51). This

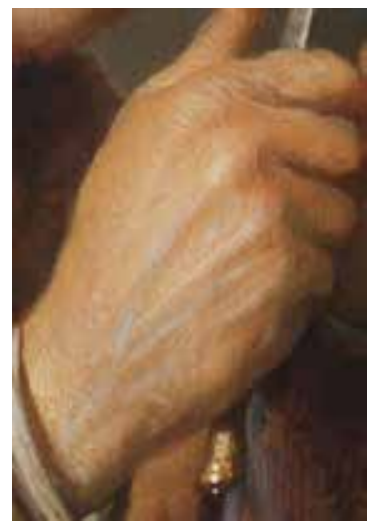

Fig. 48 Detail of Scholar Sharpening a Quill showing the brushwork of the proper right hand of the scholar

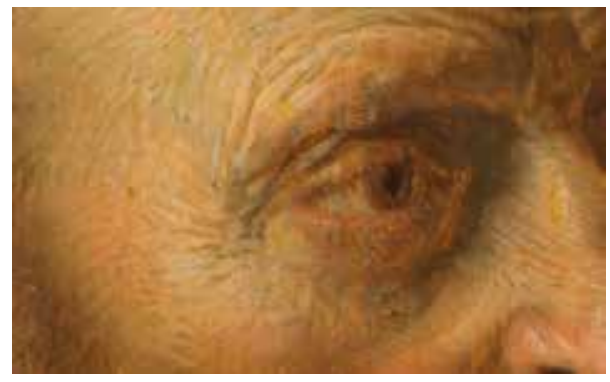

Fig. 49 Detail of Hermit Praying showing hatching brushwork around the figure's proper right eye

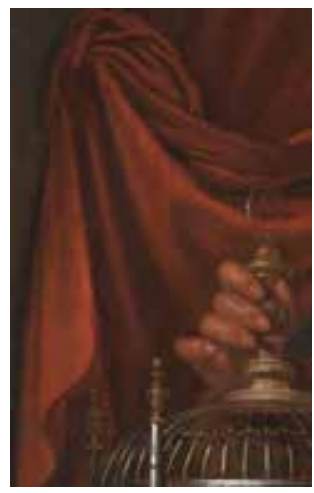

Fig. 51 Detail of Young Woman Holding a Parrot showing the hatching brushwork along the highlights of the draped curtain

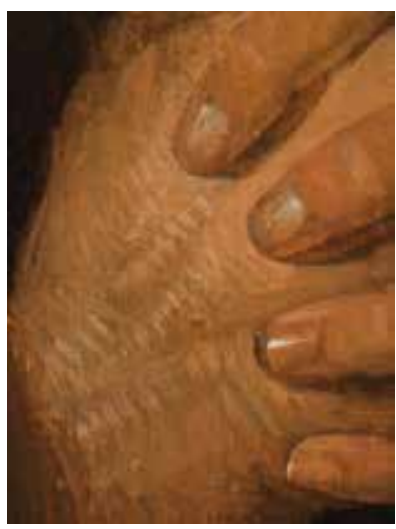

Fig. 50 Detail of Hermit Praying showing hatching brushwork along the highlights of the figure's clenched hands 
technique relates to Dou's occasional use of materials to make "stamped" impressions of textures in the paint, while here it is freely done with the brush. ${ }^{70}$ In most cases, Dou uses this hatch work to soften highlights and invigorate the texture, yet the same brushwork is also frequently visible in areas of deep shadow.

In Scholar Interrupted at His Writing, Dou's brushwork operates at times on a strikingly miniscule scale. While he carefully indicated that the book on the table is open to page "61," both the printed text of the page and the script on the folio under his quill are deliberately illegible (fig. 52). Here, Dou suggested the character of block-printed letters with measured strokes, while contrasting them with the looser handwritten script on the folio, formed with infinitesimal brushstrokes of paint (figs. 53a-b). In the darker recess of the shelf in the background, Dou unexpectedly included distinctive, yet faint, capital letters on a jar, “. . . ALVES," showing the label partially obscured by an overlapping glass container (fig. 54). ${ }^{71}$

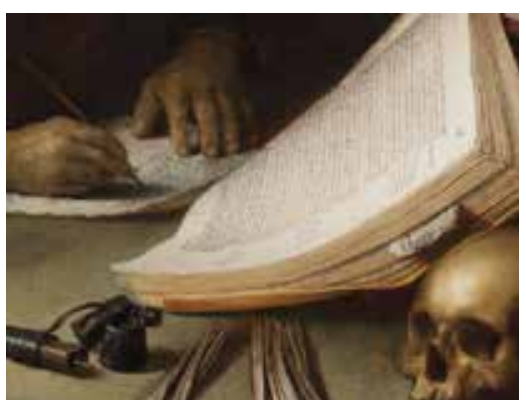

Fig. 52 Detail of Scholar Interrupted at His Writing showing the printed book and handwritten letter in the foreground

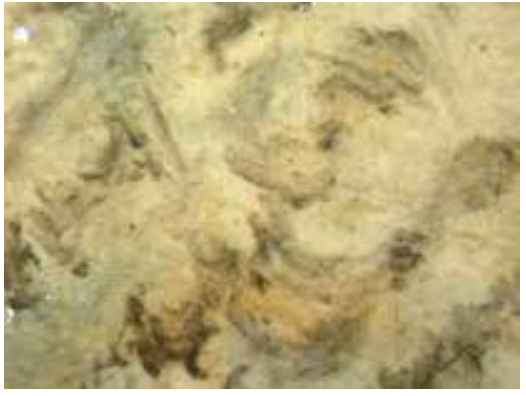

Fig. 53a Detail of Scholar Interrupted at his Writing showing, "handwritten" text of letter rendered by diluted fine black pigment applied with dithering brushstrokes, field of view: 2.75mm (photomicrograph: John Twilley)

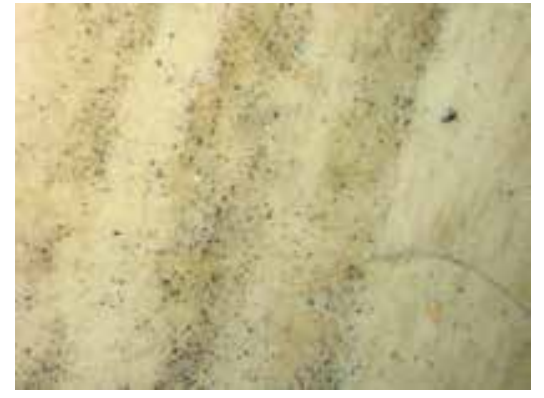

Fig. 53b "Printed" text of the book rendered by thinly dispersed coarse black pigment applied in linear strokes, field of view: $2.75 \mathrm{~mm}$ (photomicrograph: John Twilley)

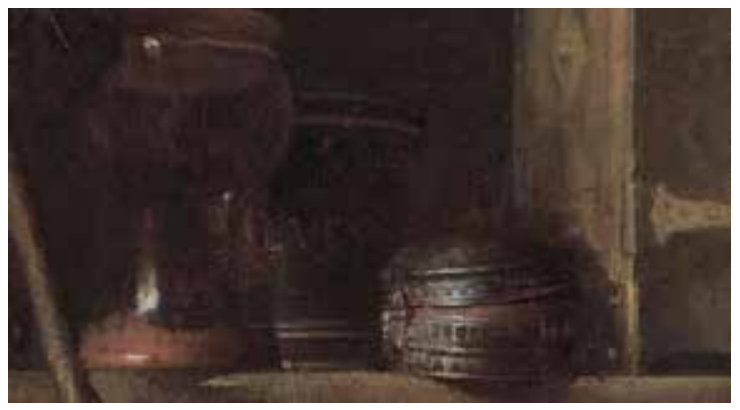

Fig. 54 Detail of Scholar Interrupted at His Writing showing the shelf in the background that includes the miniscule letters "...ALVES" on the front of a jar, partially obscured by an overlapping jar

Dou's masterful range of brushwork is particularly evident in the freely rendered curly wisps of hair that fall across the hairlines of his male and female figures. The sheer number of individual strokes that together create the appearance of a mass of plush, wavy hair is quite extraordinary (fig. 55). Dou undoubtedly used varying thicknesses of brushes to create these visual effects, some evidently executed with a brush consisting of just a few bristles (fig. 56). In a Portrait of a Lady in Profile, Dou indicated single strands of hair on the woman's temple as purely translucent, in tones of adjacent flesh color rather than as pigmented hair color (fig. 57). Dou's concept of hair as lucid texture reflecting whatever color lies behind it is also evident in his painting of the woman's fur collar. Here he dragged his brush back and forth over the whites of the woman's blouse (fig. 58). 


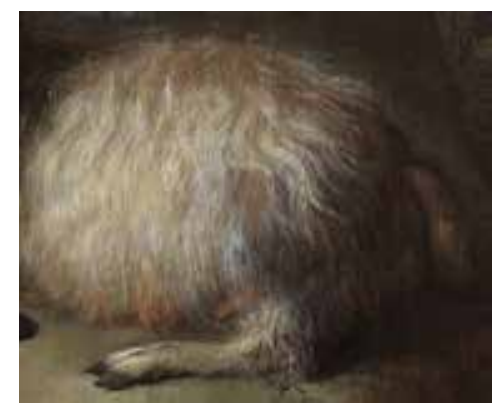

Fig. 55 Detail of Goat in a Landscape showing the complex brushwork achieved in rendering the plushness of wavy hair

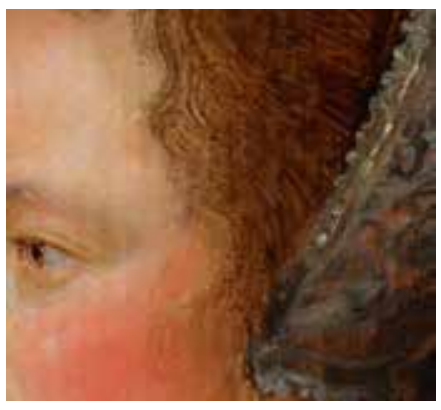

Fig. 57 Detail of Portrait of a Lady in Profile showing individual strands of hair painted in flesh tones that overlay her upper temple

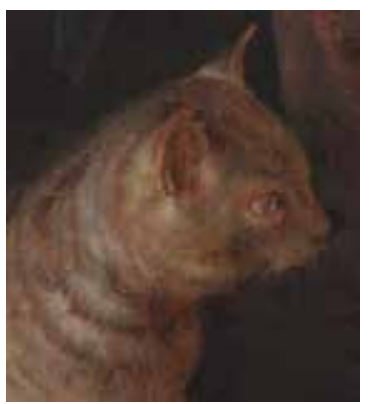

Fig. 56 Detail of Cat Crouching on the Ledge of an Artist's Atelier showing the individual bristles and brushstrokes that make up the tabby's striped pattern

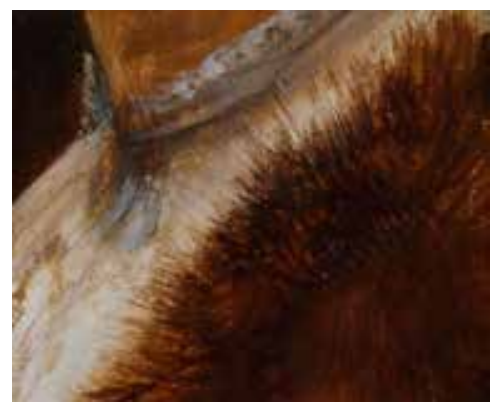

Fig. 58 Detail of Portrait of a Lady in Profile showing the fur trim painted by dragging the brush back and forth in the adjacent paint

\section{Compositional and Iconographic Changes}

44 Our examination of paintings in the Leiden Collection reveals that Dou made compositional changes during virtually all phases in the painting process. Some of these occurred in the early stages of painting among the lower strata, whereas other adjustments can be observed with the naked eye in the upper layers of paint. These changes provide insight into Dou's painting practice and indicate that a significant degree of trial and adjustment with compositional elements was integral to his work method, as scholars have also remarked in the past.

A common type of change involves adjustments to the main figure in a composition. In Goat in a Landscape, for example, the X-radiograph indicates that Dou changed the direction of the goat's head from profile to frontal (figs. 59a-b). Similar adjustments were made in a number of single figure portraits in which Dou shifted the figure to one side relative to the picture plane. This is particularly evident in Portrait of a Lady with a Music Book, in which changes along the figure's face, right arm, and shoulder seen in the X-radiograph indicate that Dou initially positioned the sitter centrally beneath the painted arch and later shifted her to the right by about $3 / 8$ inch, possibly when he modified the arched-top format (fig. 60a-b). ${ }^{72} \mathrm{~A}$ more subtle alteration is observed with the naked eye in Portrait of a Lady in Profile, in which the sitter's profile, from the hairline down to her nose, was shifted slightly to the left during the painting stage (fig. 61).

46 Dou made a series of more complex compositional changes in Old Woman at a Niche by Candlelight (fig. 12a). While Dou positioned the woman so that her candlestick breaks the picture plane and provides the painting's visual focus, its precise location was established fairly late in the paint 

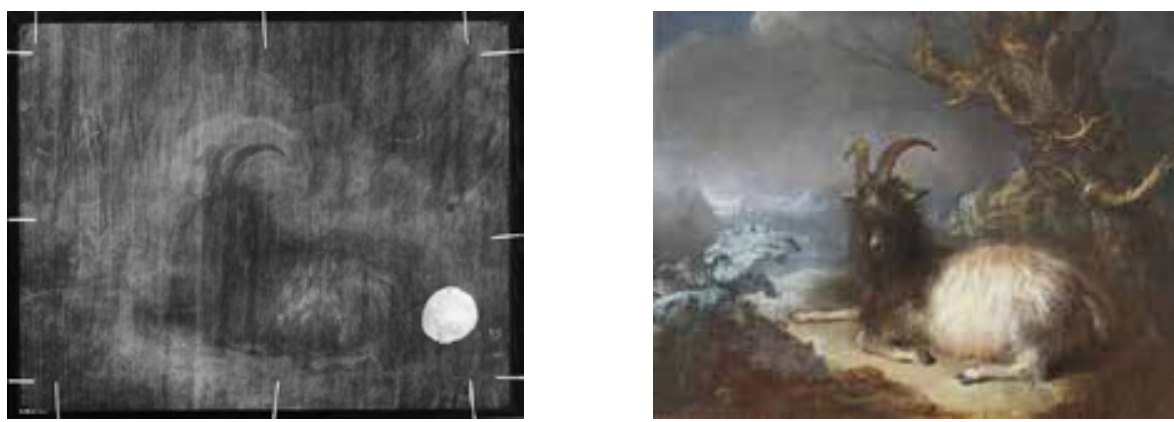

Fig. 59a X-radiograph of Goat in a Landscape showing a change from a profile to frontal view of the goat's head. Fig. 59b Visible image

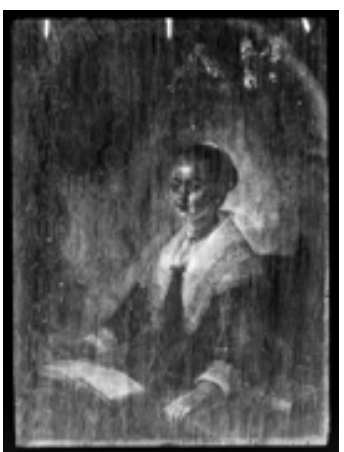

Fig. 60a X-radiograph of Portrait of a Lady with a Music Book showing a change in the arched top and a shift of the figure to the right. Fig. 60b Visible image

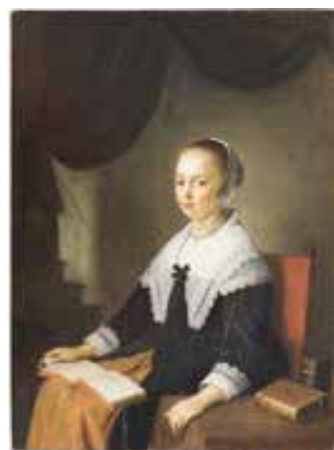

.

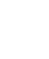



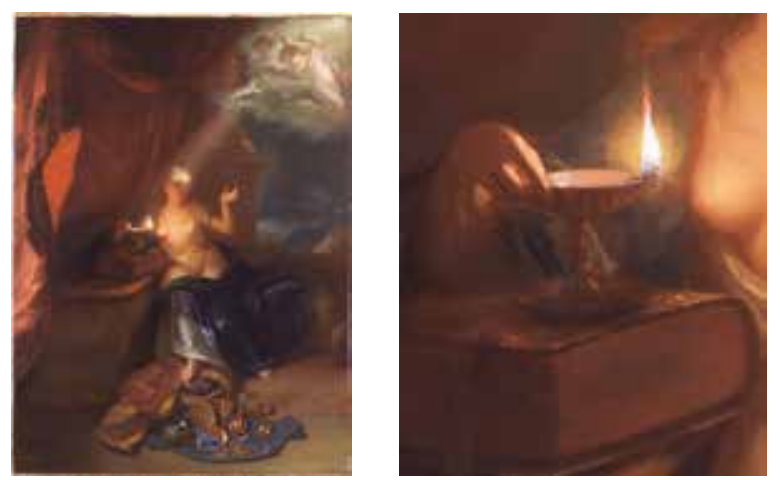

Fig. 64a Godfried Schalcken, Conversion of Mary Magdalen, signed and dated, lower left: "G. Schalcken / 1700," oil on canvas, 94 x $68.6 \mathrm{~cm}$. the Leiden Collection, New York, GS-114, showing a comparable oil lamp with the flame emerging from the side. Fig. 64b Detail of Conversion of Mary Magdalen

Similar oil lamps are depicted in paintings from the period, which show a metal oil receptacle with a flame emitting from its side (figs. $64 \mathrm{a}-\mathrm{b}$ ). ${ }^{74}$ It is not clear what meaning, if any, Dou intended with the change from an oil lamp to a candle. The highlights on the proper left side of the woman's face and the shadow on the near side of her face seem to have been defined by the original position of the oil lamp facing her, indicating that the modification occurred at a relatively late stage in the painting's execution. In the infrared image, much of the preparatory sketch work and dead coloring correspond with the earlier position of the oil lamp in the distribution of light and shadow, particularly along the ledge as well as the right and left sides of the niche (fig. 29).

Two paintings stand out as fascinating examples of more radical changes Dou made that affected the meaning of the iconography. An early work from about 1635, Scholar Interrupted at His Writing, is one of the most accomplished and finely executed works in the artist's early mature style (fig. 2a). ${ }^{75}$ The painting depicts an elderly scholar seated at a desk in the midst of writing, with his pen quill paused on paper as he looks up at the viewer. An X-radiograph reveals that Dou originally planned for an artist's easel to be a prominent element in the composition in the upper right quadrant (fig. 65a-b).$^{76}$ This compositional configuration recalls paintings attributed to the young Dou from the late 1620s and early 1630s such as Artist at His Easel, in the Leiden Collection (fig. 66) or Man Writing by an Easel, in a private collection. ${ }^{77}$ The iconography explores the concept of
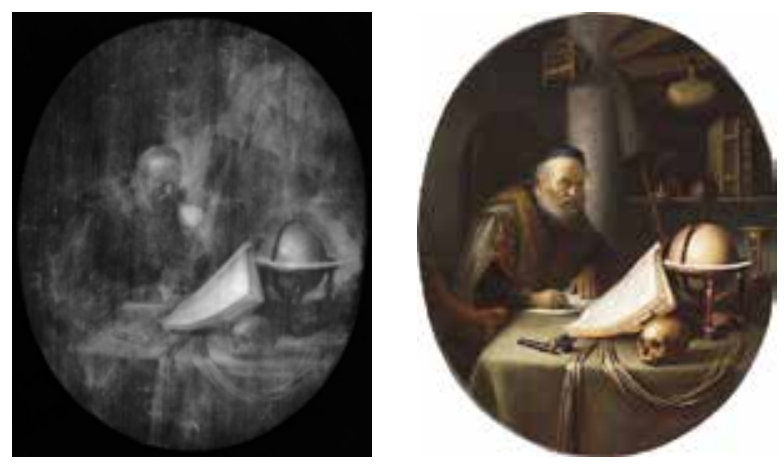

Fig. 65a X-radiograph of Scholar Interrupted at His Writing showing an earlier easel in the background. Fig. 65b Visible image

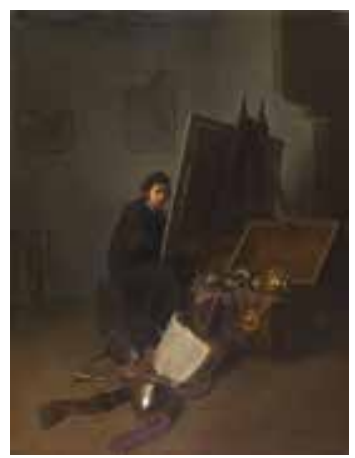

Fig. 66 Circle of Rembrandt van Rijn, possibly Gerrit Dou, An Artist in His Studio, ca. 1630, oil on panel, 66.7 x 50.8 $\mathrm{cm}$. The Leiden Collection, New York, GD-112 
the learned artist or the parallel between the artist and the scholar, a theme that Dou continued to develop even after he omitted the easel.

In the place of the easel in the central background of Scholar Interrupted at His Writing, Dou added a shelf with various small jars and books and a Japanese parasol leaning against the column. ${ }^{78}$ In an earlier stage in the composition, Dou seems to have intended other objects on the table in the foreground, possibly a lute or other books, but later painted a skull (fig. 25). ${ }^{79}$ Later in the painting stage, Dou added an hourglass, a symbol of transience, and included a slip of paper extending from the side of the book. ${ }^{80}$ Together these motifs establish, in a manner different from the obvious motif of the easel alone, an important parallel between the artist and scholar. One can assume that Dou's elder scholar is exploring questions concerning the transience of life in his own work and that he remains mindful that the wisdom and knowledge passed along through books will supersede the temporal limitations of his life. As a clever equivalent, Dou referenced the vanitas topos of art surpassing life's brevity by inserting his signature, "GDou," on a tattered piece of paper on the side of the book, adjacent to the skull (fig. 67) ${ }^{.81}$
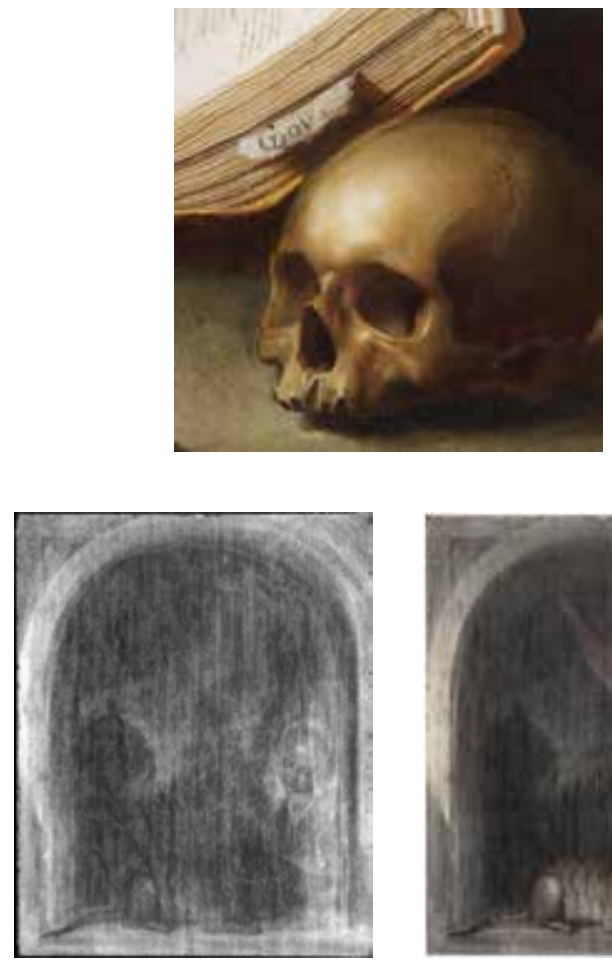

Fig. 68a X-radiograph of Cat Crouching on the Ledge of an Artist's Atelier

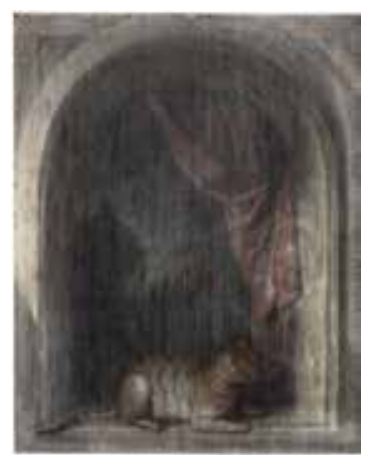

Fig. 68b X-radiograph superimposed on the visual image
Fig. 67 Detail of Scholar Interrupted at His Writing

showing the signature, "GDou," inserted on a piece of paper on the side of the book.

A second painting that underwent significant changes in iconography during the painting stage is Cat Crouching on the Ledge of an Artist's Atelier, painted at the height of Dou's career in 1657 (fig. 7a). Dou's unique depiction of a cat, a curtain draped open to view a dimly lit interior, and an artist painting at his easel was not the artist's initial concept for this work. An X-radiograph reveals that before he added the curtain on the right, Dou painted a young woman leaning forward over the ledge (figs. 68a-b). Both the IR photograph and X-radiograph show that Dou also 
painted out a small rectangular shape in the lower right corner of the windowsill that appears to have been a mousetrap (fig. 69). The object has a diagonal lever at the top and is strikingly similar to other mousetraps in paintings of the period, such as that in Dominicus van Tol's Boy with a Mousetrap, from ca. 1660-64, also in the Leiden Collection (figs. 70a-b) ${ }^{82}$
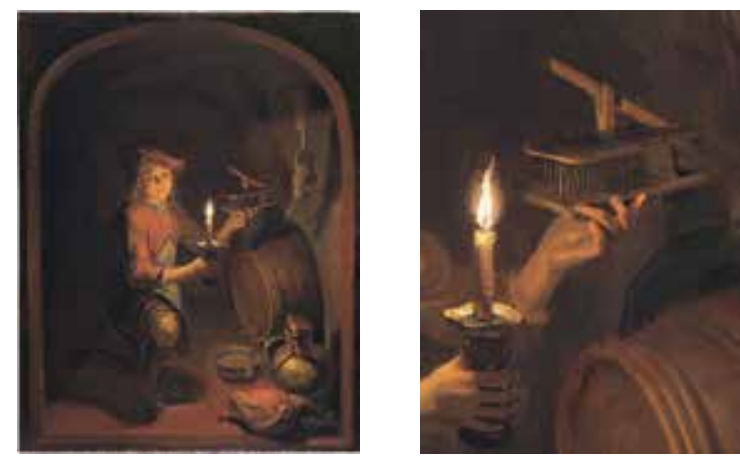

Fig. 70a Dominicus van Tol, Boy with a Mousetrap, ca. 1660-64, oil on panel, $29 \times 23 \mathrm{~cm}$. The Leiden Collection, New York, DT-100. Fig. $70 \mathrm{~b}$ Detail of Boy with a Mousetrap

While it is possible that the young woman was part of an earlier, unrelated composition, in Dou's other interior scenes featuring a mousetrap he included a figure who discovers, or presents, the trap with surprise, which may explain the woman's original role. ${ }^{83}$ The depiction of a cat watching a mousetrap was well known in the emblematic tradition, but the combination became popular in fijnschilder genre painting of the 1670 s and later. ${ }^{84}$ Because the image of a cat and mousetrap had such clear associations with love's seductive entrapment, it appears that Dou intended to allude to the theme in the earlier version of the composition.

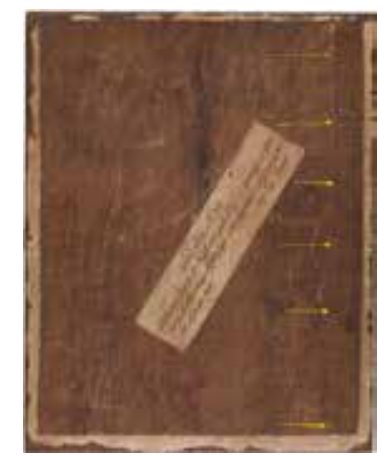

Fig. 72a Panel reverse with bevel indicated by arrows

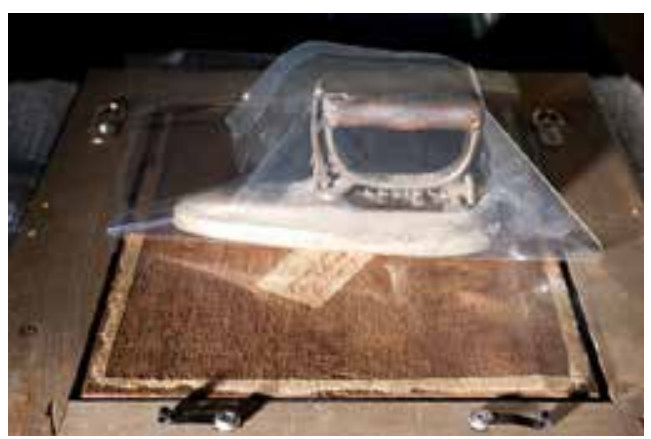

Fig. 72b Panel reverse in raking light showing bevel on left side only of Cat Crouching on the Ledge of an Artist's Atelier (photograph: Annette Rupprecht)

51 In addition to these significant changes, the X-radiograph also partially reveals the face of a masonry arch at the upper left and right corners of the niche (figs. 68a-b). These fragmented arched lines appear to extend beyond the current format and suggest that the panel was once taller and wider on the right side. Significantly, the panel's reverse is only beveled on the left side, indicating that the panel was cut or thinned down on the other three sides (figs. $72 \mathrm{a}-\mathrm{b}$ ).$^{85}$ Other remnants of an earlier composition are visible to varying degrees in both the X-radiograph and IR image, including the silhouette of a side-draped curtain, hanging from the upper left and gathered about two-thirds up the left side of the painting, as well as a circular shape at the center left that is 
reminiscent of a globe (figs. $71 \mathrm{a}-\mathrm{b}){ }^{86}$

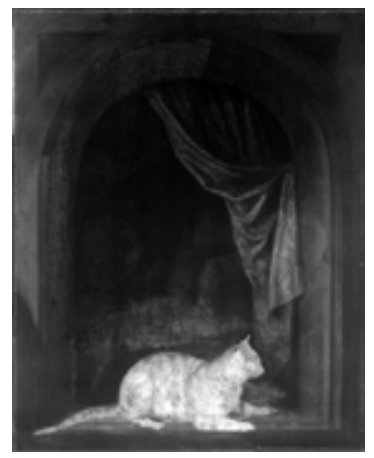

Fig. 71a Infrared image of Cat Crouching on the Ledge of an Artist's Atelier showing earlier features such as globe at center left and curtain draped to the left. InGaAs camera using 1500-1680nm filter (image: Shawn Digney-Peer)

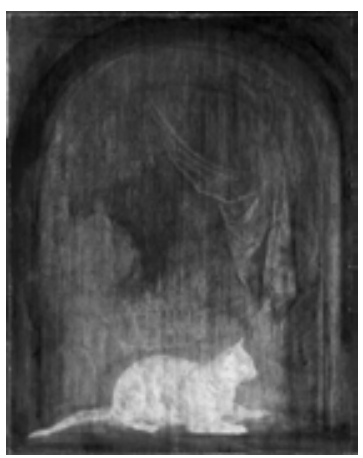

Fig. 71b Infrared image superimposed on X-radiograph with inverted density grayscale, showing earlier drape and architectural details as noted (composite: John Twilley)

52 It remains unclear which of these elements was part of a preliminary stage of the final design and which may represent an earlier, or altogether unrelated, composition. However, Dou's rendering of the cat's fur in the manner described above, over an area left in reserve where only a thin ground and the panel itself remain slightly visible through the strokes, provides clear evidence that the cat was planned from the earliest stage and the sill painted around him. In the expanded initial format, the young woman, cat, and mousetrap would have formed a plausible compositional focus, centered to the right within a larger niche frame. In this earlier configuration, the placement of the curtain on the left would have complemented the group offset on the right. Perhaps when Dou decided to omit the mousetrap and young woman, he reduced the size of the composition in order to center the cat within a smaller architectural niche. This would explain why the panel was cut down, why the curtain was painted over the young woman on the right, and why the architectural niche was depicted as a much more prominent feature in the final version, with a broader surrounding frame.

53 In the final composition, Dou made the unusual choice of depicting the cat in the niche isolated by itself. ${ }^{87}$ Eric Jan Sluijter has shown that the cat appears as an attribute of sight in late sixteenth-century prints. ${ }^{88}$ Dou seems to have expressly intended this significance and portrayed the animal as fully engaging its sense of sight, as it intently focuses on something beyond the picture plane. ${ }^{89}$ The striking illusionism of the curtain, a reference to the story of Parrhasius's famous curtain, and the scene of an artist painting at his easel in the background further reinforce the primacy of sight in artistic terms, thereby reiterating sight as the basis for the illusionism of the painting itself.

\section{Conclusion}

54 The opportunity to carry out numerous technical comparisons among the Leiden Collection works by Gerrit Dou has significantly expanded what we know of Dou's painting materials and process. Our study has confirmed several important findings made by other scholars in recent years, including Dou's frequent use of well-seasoned panels, his reliance on numerous translucent paint layers for subtle optical effects, and his tendency to make compositional changes throughout the process of painting. 
55 Our research builds on this understanding in three important ways. Microscopic examination of the paint layers has provided a new degree of certainty regarding the structure of paint applications and, thereby, a more detailed understanding of Dou's sequence of painting steps. Secondly, laboratory study of paint samples has added significantly to the very limited information previously available on Dou's choices of pigments. Consequently, we now have a clearer understanding of the roles that he chose for individual pigments and the interrelations of their behavior in Dou's multilayered constructions. The identification of Dou's pigments and their position within the sequence of paint layers has also provided a more precise view of the original appearance of these passages and allowed us to infer the roles of materials that have been lost through prior cleaning or pigment fading.

56 Finally, X-radiography and IR imaging have revealed changes that shed light on Dou's thought processes. We have learned the extent to which Dou revised his compositions, sometimes making quite radical changes that materially affected the overall meaning. The examination of the underlayers of paint through this technology has also aided our understanding of Dou's preparatory design work and technique. Dou, of course, adopted the method of sketching directly onto the ground and working up the composition from his teacher Rembrandt -- a practice that, for both artists, invariably led to revisions or changes as the idea for each work developed during the painting process. In addition to what we learned from this technical study about Dou's painting process and method, we also have glimpsed what he must have learned from his master. Similarly, as research is carried out on the technique of Dou's pupils, we can expect that this will, in turn, shed additional light on what they learned from Dou.

\section{Appendix}

\section{Instrumental Methods}

The technical study that underpins this essay may be loosely divided into two categories: examination methods and analytical methods. Technologically based examination methods included the use of magnification aids for visual examination, such as low magnification stereobinocular microscopy, several forms of infrared imaging, ultraviolet fluorescence examination, and X-ray radiography (contributors to these phases include conservators Shawn Digney-Peer, Annette Rupprecht, and Nancy Krieg, and radiographer Peter Branch, as noted). In the case of infrared examination, the terminology of the field has not kept pace with instrumental developments. The retention of terms based upon distinctions in the capabilities of film and vidicon IR devices is problematic and counterproductive with the advent of digital photography based on CCD detectors that extend the range of SLR cameras into the near infrared. It is more essential than ever to specifically identify the range of the IR spectrum accessed by the equipment in use. For these reasons we prefer the use of "infrared imaging" supplemented by appropriate details, in preference to terms such as "infrared photography" and "infrared reflectography" or "IRR." Instrumental analytical methods for identification of the materials of the paintings were carried out by one of the authors (Twilley) and included the preparation of cross sections for optical examination at high magnification in reflected light, by ultraviolet fluorescence microscopy, and by Scanning Electron Microscopy (SEM). Elemental analyses were carried out on both cross sections and paint fracture fragments in the course of SEM examination using energy-dispersive $\mathrm{X}$-ray spectrometry. In a few cases, cross sections were subsequently reduced to thin sections 
of 10 microns thickness for examination in transmitted light using the polarizing microscope. Pigment dispersions were examined as slide mounts using the polarizing microscope, whereby optical properties of individual pigment particles may be tested for characteristics such as refractive index, birefringence, pleochroism, cleavage, and crystal habit. Raman microspectroscopy was used for identification of pigments as loose particles, in slide mounts and in cross sections, as necessary. Exceptionally, we employed darkfield metallographic microscopy at magnifications up to $1,000 \mathrm{x}$ directly on the painting or rear support surface (GD-102 and GD-111, respectively).

\section{Examination Methods}

Nikon D700 UV/IR modified CCD camera with longpass filters at 780, 850, and 1000 nanometers (Rupprecht)

FLIR Alpha NIR InGaAs camera with bandpass filter, effective range of 1500-1680 nm (DigneyPeer)

Nikon 995 CCD camera, modified for IR use, with bandpass filters as follows, all used for normal and macro-scale imaging (Twilley):

$785 \mathrm{~nm}$, fwhm=20 nm (Omega);

$815 \mathrm{~nm}$, fwhm=90 nm (Omega);

$880 \mathrm{~nm}$, fwhm=10 nm (Omega);

$905 \mathrm{~nm}$, fwhm=35 nm (Omega); and

$1000 \mathrm{~nm}$, fwhm=70 nm (ThermoCorion).

Nikon 995 CCD camera, modified for IR use, with $875 \mathrm{~nm}$ longpass filter (Omega), for IR documentation of microscopic features (effective wavelength 875-1050 nm) using the stereobinocluar microscope (Twilley)

Hamamatsu infrared vidicon camera C2741-03 with one of the following filters, each used with iterative frame averaging of 128 frames. (Twilley):

broadband 1100-1600 nm (Omega);

broadband 1230-1580 nm (Spectrogon);

broadband 1485-1665 nm (Omega);

$1500 \mathrm{~nm}$ longpass filter (Omega); or

$1600 \mathrm{~nm}$ longpass filter (CVI Laser Corp.)

$\mathrm{X}$-ray radiography was carried out as part of a larger radiography campaign on a wider group of paintings in the Leiden Collection in 2009 by Peter Branch of Branch Radiographic Laboratories in Cranford, New Jersey. Digital radiography was employed, due to constraints imposed by the gallery premises. An Xscan CR unit with $14 \times 17$ inch plate was used with an air-cooled X-ray tube. Exposure conditions were optimized for the needs of individual paintings. Typical exposures required were $35-40 \mathrm{kV}$ at $4.5 \mathrm{mAsec}$. Images were extracted into QPCXSCAN32 (iCRco, Inc., Torrance, CA) in the DICOND format at $254 \mathrm{dpi}, 16$ bit grayscale, and exported for further processing in Photoshop.

Analytical Methods (Twilley)

Cross sections were embedded under vacuum in low molecular weight epoxy cured with a cycloaliphatic amine hardener (Hxtal) at 60 degrees Celsius. Grinding and polishing were carried out using successive grades of silicon carbide abrasive paper through 600 mesh, terminating with 1 micron aluminum oxide suspended in aliphatic hydrocarbon fluid on napless nylon fabric. Scanning electron microscope: Leo1550, utilizing a Schottky FEI source and both secondary and 
backscatter electron imaging modes. Fracture sections and particulate samples were adhered to conductive carbon tape. Both fracture sections and embedded cross sections were rendered conductive by coating with vacuum-evaporated carbon prior to examination. Beam accelerating voltage was typically $20 \mathrm{kV}$ for backscatter imaging. Secondary electron imaging of low-density structures was conducted at $12 \mathrm{kV}$ when necessary.

X-ray spectrometer: Edax energy dispersive $\mathrm{Si}(\mathrm{Li})$ drifted detector. Spectra were collected and processed via an iXRF Corp. interface and Iridium software.

Raman spectroscopy: Chromex Senturion dispersive Raman spectrometer, $785 \mathrm{~nm}$ excitation, spectra were collected in Stokes mode over the range of 180-1680 cm-1, with resolution of $4 \mathrm{~cm}-1$ Polarized light microscopy: Nikon Microphot SA pol, using 1x, 4x, 10x, 20x, 40x, 60x and 100x planapochromat objectives.

Ultraviolet fluorescence microscopy: Nikon Microphot FXA, using 4x, 10x, 20x, and 40x planapofluor objectives with a Nikon UV20 filter block (UV excitation, full visible spectrum emission). Metallographic (darkfield reflected light) microscopy: Olympus modular wafer-inspection microscope using brightfield/darkfield, infinity-corrected 5x, 20x, 50x, and 100x LMPlanfl objectives. The dendrochronological analyses were performed by both UK-based dendrochronologist Ian Tyers, and Hamburg-based dendrochronologist Peter Klein.

Unless otherwise noted, all observations and conclusions are those of the authors.

\section{Acknowledgements}

In commemoration of Gerrit Dou's four hundredth birthday, 2013 marks the year in which the groundwork for this article was prepared as a result of presentations given on various related topics by the authors at the following conferences: the CODART ZESTIEN Congress in Vienna, April 21-23, 2013; Rembrandt and His Circle: An International Colloquium, organized by Queen's University for the Bader International Study Center at Herstmonceux Castle, July 18-21, 2013; and Painting Techniques: An International Symposium at the Rijksmuseum, Amsterdam, September 18-20, 2013. The authors wish to thank Arthur K. Wheelock Jr. and the two anonymous readers of the manuscript for their valuable comments on earlier versions of this article.

Dominique Surh is Curator of the Leiden Collection, having joined the organization at its inception in 2005. Surh oversees research, technical studies, and is a co-author of the collection's online scholarly catalogue (forthcoming, May 2014, www. theleidencollection.com). Surh completed her PhD at the University of Virginia. Dsurh@theleidencollection.com

Ilona van Tuinen is Assistant Curator of the Leiden Collection and co-author of the collection's online catalogue. She joined the organization in 2011, after completing her research Master's in art history at the University of Amsterdam and working at the Museum de Lakenhal in Leiden as assistant and catalogue editor for the 2011 exhibition Lucas van Leyden and the Renaissance. Ivantuinen@theleidencollection.com

John Twilley, FIIC, FAIC, was formerly Conservation Scientist of the J. Paul Getty Museum and Head of Conservation Research of the Los Angeles County Museum of Art (1985-99). Since 1999 he has worked independently on the applications of microanalysis to the study of artist's materials, techniques, and the problems of pigment alteration. jtwilley@sprynet.com 


\section{List of Illustrations}

Figs. 1a-b (a) Gerrit Dou, Scholar Sharpening a Quill, ca. 1630-35, oil on panel, 25 x $20.5 \mathrm{~cm}$, oval, signed,centerright, underquill, “GD”(GD in ligature). The Leiden Collection, New York, GD-104 (b) verso

Figs. 2a-b (a) Gerrit Dou, Scholar Interrupted at His Writing, ca. 1635, oil onpanel, 24.5 x $20 \mathrm{~cm}$, oval, signed, on a piece of paper protruding from the book, "GDov" (GD in ligature). The Leiden Collection, New York, GD-102 (b) verso

Figs. 3a-b (a) Gerrit Dou Portrait of a Young Man with a Hat, ca. 1635, oil on panel, 38 x30.5 cm. The Leiden Collection, New York,GD-100 (b) verso

Figs. 4a-b (a) Gerrit Dou, Portrait of a Lady in Profile, ca. 1635-40, oil on panel, oval inlaid into a rectangular panel, $13.3 \times 11.3 \mathrm{~cm}$, signed, left center, "GDou" (GD in ligature). The Leiden Collection, New York, GD-110 (b) verso

Figs. 5a-b (a) Gerrit Dou, Portrait of a Gentleman with a Walking Stick, ca. 1645, oil on panel, 49.2 x $39.7 \mathrm{~cm}$, signed, right, "GDou"(GD in ligature). The Leiden Collection, New York, GD-113 (b) verso

Figs. 6a-b (a) Gerrit Dou, Portrait of a Lady with a Music Book, ca. 1640-44, oil on panel, $27.1 \mathrm{x}$ $19.8 \mathrm{~cm}$, signed, on the book, "GDou"(GD in ligature). The Leiden Collection, New York, GD-116 (b) verso

Figs. 7a-b (a) Gerrit Dou, Cat Crouching on the Ledge of an Artist's Atelier, 1657, oil on panel, 34 x $26.7 \mathrm{~cm}$, signed and dated, on the ledge, "GDou 1657"(GD in ligature). The Leiden Collection, New York,GD-108 (b) verso

Figs. 8a-b (a) Gerrit Dou, Portrait of Dirck van Beresteyn, ca. 1652, oil on silver-copper alloy support, oval, $10 \times 8 \mathrm{~cm}$, signed, upper right, "GDou"(GD in ligature). The Leiden Collection, New York, GD-111 (b) verso

Figs. 9a-b (a) Gerrit Dou, Young Woman Holding a Parrot, ca. 1660-65, oil on panel, 24.8 x18.6 $\mathrm{cm}$. The Leiden Collection, New York, GD-105 (b) verso

Figs. 10a-b (a) Gerrit Dou, Goat in a Landscape, ca. 1660-65, oil on panel, $19.5 \times 24.9 \mathrm{~cm}$, signed, lower center, "GDou"(GD in ligature). The Leiden Collection, New York, GD-114 (b) verso

Figs. 11a-b (a) Gerrit Dou, Hermit Praying, ca. 1665-70, oil on panel, 18 x $12.9 \mathrm{~cm}$, signed, center right, "GD”(GD in ligature). The Leiden Collection, New York,GD-107(b)verso

Figs. 12a-b (a) Gerrit Dou,Old Woman at a Niche by Candlelight, 1671, oil on panel, 26.7 x20.8 $\mathrm{cm}$, signed, bottom center, "GDovAnno 1671"(GD in ligature). The Leiden Collection, New York, GD-103 (b) verso 
Figs. 13a-b (a) Gerrit Dou, Herring Seller and a Boy, ca. 1664, oil on panel, $42.3 \times 33.3 \mathrm{~cm}$, signed, bottom center, "GDou”(GD in ligature). The Leiden Collection, New York, GD-106 (b) verso

Fig. 14 Detail of the cloak of the scholar's proper right shoulder of Scholar Interrupted at His Writing showing losses that reveal a rust-colored sketch over a light-colored ground and primuersel, field of view: $2.75 \mathrm{~mm}$ (photomicrograph: John Twilley)

Fig. 15 Infrared image detail of Scholar Sharpening a Quill showing line underdrawings of the book and hourglass, together with a broader-brushed sketch at the top rim of the book. InGaAs camera using 1500-1680nm filter (image: Shawn Digney-Peer)

Fig. 16 Infrared image detail of Scholar Interrupted at His Writing showing underdrawing and modeling around birdcage at the upper center. InGaAs camera using 1500-1680nm filter (image: Shawn Digney-Peer)

Figs. 17a-b Detail of Scholar Interrupted at His Writing showing visual detail of ear with faint sketch lines, field of view: $11 \mathrm{~mm}$ (b) infrared image detail of the face, $875-1100 \mathrm{~nm}$ filter (photomicrographs: John Twilley)

Fig. 18 Infrared image of Portrait of a Lady with a Music Book showing delicate line drawing around the books, as well as vigorous undermodeling of the woman's outer gown, in the dead coloring phase. InGaAs camera using 1500-1680nm filter (image: Shawn Digney-Peer)

Fig. 19 Infrared image detail of Portrait of a Lady with a Music Book showing the line underdrawing of the book on the woman's lap. InGaAs camera using 1500-1680nm filter (image: Shawn Digney-Peer)

Fig. 20 Infrared image detail of Portrait of a Lady with a Music Book showing the line underdrawings of the books on the table at the far right. In GaAs camera using 1500-1680nm filter (image: Shawn Digney-Peer)

Fig. 21 Infrared image detail of Hermit Praying showing underdrawing of the hands, 800-900nm filter (photograph: John Twilley)

Fig. 22 Infrared image of Hermit Praying showing vigorous undermodeling in the cloak and changes along both shoulders, 950-1000nm filter (image: John Twilley)

Figs. 23a-b(a) Infrared image of Portrait of a Gentleman with a Walking Stick showing initial sketch of arched doorway in the background and column with base on the left. InGaAs camera using 1500-1680nm filter (image: Shawn Digney-Peer) (b)Visible image

Figs. 24a-b (a) Infrared image detail of Portrait of a Gentleman with a Walking Stick showing changes in the collar, lapel, or breastplate during the preparatory stage, 1000-1050nm filter (image: AnnetteRupprecht) (b) Visible image 
Fig.25 Infrared image of Scholar Interrupted at His Writing showing broad brushwork in the scholar's garment and along the front of the table. InGaAs camera using 1500-1680nm filter (image:ShawnDigney-Peer)

Fig. 26 Infrared image of Scholar Sharpening a Quill showing brushed sketch work of scarf around scholar's neck and original position of the inkwell. InGaAs camera using 1500-1680nm filter (image: Shawn Digney-Peer)

Figs. 27a-b (a) Infrared image detail of Scholar Sharpening a Quill showing the brush sketch in the scarf around the scholar's neck and the dead coloring around the figure's proper left hand knuckles. InGaAs camera using 1500-1680nm filter (image: Shawn Digney-Peer) (b) Visible image

Figs. 28a-c: Sample from the cloak of Scholar Sharpening a Quill showing the violet-brown dead color and upper violet lake layer (a) Cross section in reflected light (the top layer is retained only at the left end), 200x (b) UV autofluorescence differentiating the two layers, 200x (c) Partially dispersed pigments from both layers showing particles of lake from the top layer and iron earth pigment with Kassel earthfrom the dead coloring, transmitted light with partially crossed polars, 400x (photomicrographs: JohnTwilley)

Fig. 29 Infrared image of Old Woman at a Niche by Candlelight showing broadly brushed sketch work in the initial design phase. InGaAs camera using1500-1680nm filter (image: Shawn DigneyPeer)

Fig. 30 Infrared image of Herring Seller and a Boy, 1000-1050nm filter (image: Annette Rupprecht)

Fig. 31 Infrared image of Young Woman Holding a Parrot, 1000-1050nm filter (image: Annette Rupprecht)

Fig. 32 Detail of Portrait of Dirck van Beresteyn showing the fine craquelure in the blue background near the mid-left edge, field of view: $6 \mathrm{~mm}$ (photomicrograph: John Twilley)

Fig. 33 Dispersed pigments from Portrait of Dirck van Beresteyn showing dark gray paint containing lead white, boneblack, well-preserved smalt, and isotropic hydrated iron oxide (goethite), transmitted light with partially crossed polars, 400x (photomicrograph: John Twilley)

Figs. 34a-b (a) Smalt grainfrom the blue background of Portrait of Dirck van Beresteyn (with adhering lead white particles), back scatter electron image, 4,720x (b) Elemental composition obtained by X-ray spectrometry during SEM observation. Cobalt in a potash-silica glass is responsible for its blue color. Arsenic detected here is a typical contaminant in cobalt ores used for the coloring of smalt (electron micrograph: John Twilley)

Fig. 35 Detail of Scholar Interrupted at His Writing showing the scarf on the tablecloth emerging from beneath the book where a fine crack disclosed a series of blue layers beneath, field of view: $3.6 \mathrm{~mm}$ (photomicrograph: John Twilley) 
Figs. 36a-c (a) Cross section from Scholar Interrupted at His Writing showing a) a thin section of the upper layers from the book shadow on the scarf atop the tablecloth, after reduction to $10 \mathrm{mi}^{-}$ crons in thickness, as viewed in transmitted light between crossed polars (b)The section as viewed using ultraviolet fluorescence microscopy (c) Backscatter electron micrograph showing the dearth of lead white apart from those areas on the left disturbed by lead soap formations from layers beneath. The uppermost layer contains vivianite that has transformed from blue to yellow. Indigo masks the bire fringence of azurite and calcite in the intermediate layers, obscuring distinctions among those layers in transmitted light while they can be differentiated into distinct layers by UV fluorescence microscopy,500x (photomicrographs and electron micrograph: John Twilley)

Fig. 37 Cross section detail from the scarf over the tablecloth in Scholar Interrupted at His Writing showing the upper blue strata in the SEM. The low contrast in this backscatter electron image shows the dearth of heavy elements in these layers, including lead white pigment, and implies that they were all intended to be translucent. X-ray spectrometry shows that iron phosphate is common in the top layer (corresponding to the yellow observed in the thin section), and that calcite and gypsum are common in the thicker stratum just beneath. The organic colorant indigo,responsible for blue color in this stratum, is not detectable by this method. Azurite occurs in the lower stratum included in this view, 5,850x (electron micrograph: John Twilley)

Figs. 38a-b X-ray spectra from the upper most yellow layer of the scarf in Scholar Interrupted at His Writing (cross hair in Fig. 37) showing (a) layer composition as a whole, with pigmentation by vivianite and calcite with an ear absence of lead white (b) iron phosphate in individual degraded vivianite particles

Figs. 39a-b Partially dispersed pigments from the intermediate layers from the tablecloth and scarf sequence in Scholar Interrupted at His Writing demonstrating the presence of isotropic indigo along with birefringent calcium carbonate. Polarized light microscopy in transmitted light (a) with polars (b) without polars, 1,000x (photomicrograph: John Twilley)

Fig. 40 Detail of a stripped state photo during treatment of Goat in a Landscape showing losses in the sky along striations of the wood grain at the upper left, revealing the gray dead coloring underneath the uppermost layer of ultramarine (photograph: Nancy Krieg)

Figs. 41a-c Cross section of a sample from the sky of Goat in a Landscape showing the ground, primuersel, blue-gray dead coloring, and final blue layers (a) Cross section in reflected light (b)Thin section in transmitted light with crossed polars (c)Ultraviolet autofluorescence showing subdivisions in primuersel, 100x (photomicrographs: John Twilley)

Figs. 42a-b Dispersed pigments from the sky of Goat in a Landscape showing particles of isotropic natural ultramarine from the uppermost blue stratum that illustrate its great diversity of particle sizes, all in good condition, transmitted light with partially crossed polars, 400x (both images) (photomicrographs: John Twilley)

Fig. 43 Partially dispersed pigment from the blue-gray dead coloring of the sky of Goat in a Land- 
scape showing fine ultramarine, lead white and black, demonstrating that this was a purposeful blue-gray mixture and not the result of ultramarine degradation, in transmitted light with crossed polars, 400x (photomicrographs: John Twilley)

Fig. 44 Detail of a leaf in the foreground of Goat in a Landscape showing deep blue color and the use of yellow ochre for the vein, field of view: $2.75 \mathrm{~mm}$ (photomicrograph: John Twilley)

Figs. 45a-d Cross section of a sample from the foreground leaf of Goat in a Landscape showing underlying pale yellow application that has been painted out (a) Cross section in darkfield reflected light, 125x (b) Thin section in transmitted light with crossed polars, $125 \mathrm{x}$ (c)UV autofluorescence showing yellow-fluorescing lakes, including those in opaque lower layers, $125 \mathrm{x}$ (d) Backscatter electron image showing additional layer differentiation. At least nine layers are present as noted (photomicrographs and electron micrograph: John Twilley)

Fig. 46 Detail of Herring Seller and a Boy showing mid-tones in the face of the old woman achieved by dark undermodeling, superimposed with translucent flesh tones and additional highlights

Fig. 47 Detail of Young Woman Holding a Parrot showing the birdcage, an area that represents Dou's working method of painting in sequential planes from the rear to the front

Fig. 48 Detail of Scholar Sharpening a Quill showing the brushwork of the proper right hand of the scholar

Fig. 49 Detail of Hermit Praying showing hatching brushwork around the figure's proper right eye

Fig. 50 Detail of Hermit Praying showing hatching brushwork along the highlights of the figure's clenched hands

Fig.51 Detail of Young Woman Holding a Parrot showing the hatching brushwork along the highlights of the draped curtain

Fig. 52 Detail of Scholar Interrupted at His Writing showing the printed book and handwritten letter in the foreground

Figs. 53a-b Details of Scholar Interrupted at his Writing showing (a) "handwritten" text of letter rendered by diluted fine black pigment applied with dithering brushstrokes (b) "printed" text of the book rendered by thinly dispersed coarse black pigment applied in linear strokes, field of view for both: $2.75 \mathrm{~mm}$ (photomicrographs: John Twilley)

Fig. 54 Detail of Scholar Interrupted at His Writing showing the shelf in the background that includes the miniscule letters "...ALVES" on the front of a jar, partially obscured by an overlapping jar

Fig. 55 Detail of Goat in a Landscape showing the complex brushwork achieved in rendering the 
plushness of wavy hair

Fig. 56 Detail of Cat Crouching on the Ledge of an Artist's Atelier showing the individual bristles and brushstrokes that make up the tabby's striped pattern

Fig. 57 Detail of Portrait of a Lady in Profile showing individual strands of hair painted in flesh tones that overlay her upper temple

Fig. 58 Detail of Portrait of a Lady in Profile showing the fur trim painted by dragging the brush back and forth in the adjacent paint

Figs. 59a-b (a) X-radiograph of Goat in a Landscape showing a change from a profile to frontal view of the goat's head (b) Visible image

Figs. 60a-b (a) X-radiograph of Portrait of a Lady with a Music Book showing a change in the arched top and a shift of the figure to the right (b) Visible image

Fig. 61 Detail of Portrait of a Lady in Profile showing a change in the woman's upper profile

Figs. 62a-b (a) X-radiograph of Old Woman at a Niche by Candlelight showing the original flame of the oil lamp at the center right (b) Visible image

Figs. 63a-b (a) Stripped-state photo of Old Woman at a Niche by Candlelight (photograph: Nancy Krieg) (b) Detail of a stripped state photo showing the earlier position of the woman's proper left arm and hand, which originally rested on the middle of the base of an oil lamp. The original flame of the lamp emerged from the left side of the metal receptacle, where the old woman's proper left fingers are now located (photograph: Nancy Krieg)

Figs. 64a-b (a) Godfried Schalcken, Conversion of Mary Magdalen, signed and dated, lowerleft: “G. Schalcken/ 1700,"oil on canvas, 94 x68.6 cm. the Leiden Collection, New York, GS-114, showing a comparable oil lamp with the flame emerging from the side (b) Detail of Conversion of Mary Magdalen

Figs. 65a-b(a) X-radiograph of Scholar Interrupted at His Writing showing an earlier easel in the background (b) Visible image

Fig. 66 Circle of Rembrandt van Rijn, possibly Gerrit Dou, An Artist in His Studio, ca. 1630, oil on panel, 66.7 x $50.8 \mathrm{~cm}$. The Leiden Collection, New York, GD-112

Fig. 67 Detail of Scholar Interrupted at His Writing showing the signature, "GDou,"inserted on a piece of paper on the side of the book.

Figs. 68a-b (a) X-radiograph of Cat Crouching on the Ledge of an Artist's Atelier (b) X-radiograph superimposed on the visual image, composite: John Twilley 
Fig. 69 Infrared image detail showing what appears to be a mousetrap in the lower right corner. InGaAs camerausing 1500-1680nm filter (image: Shawn Digney-Peer)

Figs. 70a-b (a) Dominicus van Tol, Boy with a Mousetrap, ca. 1660-64, oil on panel, 29 x23 cm. The Leiden Collection, New York, DT-100 (b) Detail of Boy with a Mousetrap

Figs. 71a-b(a) Infrared image of Cat Crouching on the Ledge of an Artist's Atelier showing earlier features such as globe at center left and curtain draped to the left. InGaAs camera using 15001680nm filter (image: Shawn Digney-Peer) (b) Infrared image superimposed on X-radiograph with inverted density grayscale, showing earlier drape and architectural details as noted (composite: John Twilley)

Figs. 72a-b (a) Panel reverse with bevel indicated by arrows (b) Panel reverse in raking light showing bevel on left side only of Cat Crouching on the Ledge of an Artist's Atelier (photograph: Annette Rupprecht)

${ }^{1}$ For an overview of Gerrit Dou's reputation throughout the centuries, see Arthur K. Wheelock Jr., "Dou's Reputation," in Ronni Baer, Gerrit Dou 1613-1675: A Master in the Age of Rembrandt, exh. cat. (Washington, D.C.: National Gallery of Art; London: Dulwich Picture Gallery; The Hague: Royal Cabinet of Paintings Mauritshuis, 2000-2001), 12-24. In the century between the publication of Theopile Thorés devastating opinion on Dou in his famous Musées de la Hollande (Paris, 1858-60) and Jan Emmens's positive reevaluation of Dou in the 1960s, the artist was virtually forgotten. Important studies on Dou since the 1960s include Ronni Baer, "The Paintings of Gerrit Dou (1613-1675)" (PhD diss., New York University, 1990), and the exhibition Gerrit Dou 16131675 (see above), curated by Ronni Baer. See esp. pp. 39-42 in this exhibition catalogue, where Baer discusses Dou's working method.

${ }^{2}$ Luuk Struick van der Loeff and Karin Groen, "Probleem, Overwegingen en Beslissingen bij de Conservatie en Restauratie van het Schilderij door Gerard Dou 'Jonge Moeder', Mauritshuis, 1658, inv.nr. 32," Centraal Laboratorium Themadag 12 (1987): 40-50. A slightly more elaborate, English version of this article appeared as Luuk Struick van der Loeff and Karin Groen, "The Restoration and Technical Examination of Gerard Dou's Young Mother in the Mauritshuis," in ICOM Committee for Conservation: $10^{\text {th }}$ Triennial meeting, Washington, DC, ed. Janet Bridgland (Lawrence, Kansas: Allen Press, 1993), 98-103. In the present article, the English version will be cited.

${ }^{3}$ Struik van der Loeff and Groen, "Restoration," 100: Dou not only changed the position of the head of the young girl behind the cradle, he also appears to have adjusted the date from 1652/3 to 1658 , possibly because the original commission of the painting was abandoned in $1652 / 3$ due to the death of the patron. Dou probably revisited the painting in 1658, just before it was purchased by the Staten van Holland and West-Friesland to be part of the 1660 diplomatic "Dutch gift" to Charles II, king of England.

${ }^{4}$ Struik van der Loeff and Groen, "Restoration," 102-3. Struick van der Loeff and Groen noted the presence of an astonishing twelve layers of alternating brown and black paint underneath the yellow of the lamp.

${ }^{5}$ Eric Jan Sluijter, De lof der schilderkunst: Over schilderijen van Gerrit Dou (1613-1675) en een 
traktaat van Philips Angel uit 1642 (Hilversum: Verloren, 1993).

${ }^{6}$ Sluijter, Lof der schilderkunst, 58-71: this combination of a high level of detail and loose brushstrokes was already noted by (near-) contemporary art theorists and biographers. In his Nieuwe Schouburgh (The Hague, 1750), vol. 2, p. 4, Johan van Gool speaks of a "zwierige lossigheit," and Philips Angel in his Lof der Schilderkonst (Leiden, 1642) of "eyghentlijck," as well as "los," which can mean realistic as well as loose. Sluijter further remarks that Karel van Mander used exactly this contrast to describe the work of Lucas van Leyden, Dou's famous early sixteenth-century predecessor, and suggests that Dou was modeling himself after Lucas's work, whether he was conscious of it or not.

${ }^{7}$ Friso Lammertse, "Veranderen na verloop van jaren: Over Gerard Dou’s Kwakzalver in Rotterdam en het Zelfportret in Kansas City," in Album Discipulorum J. R. J. van Asperen de Boer, ed. Peter van den Brink and Liesbeth M. Helmus (Zwolle: Waanders, 1997), 111-20, esp. 116-19. Both works include the later 1667 design of the Blauwe Poort gate. In both cases, it appears that Dou was not reworking an already existing gate, but rather added the entire gate in or after 1667. In the case of the Kansas City Self-Portrait, Dou also added other elements, such as the carpet under his proper right arm, at the same time that he added the gate.

${ }^{8}$ Annetje Boersma, "Dou's Painting Technique: An Examination of Two Paintings," in Gerrit Dou 1613-1675, exh. cat. (see note 1 above), 54-63.

${ }^{9}$ Boersma, "Dou's Painting Technique," 59: whereas the finely ground ultramarine Dou used for his blue pigment in the Rotterdam Lady at Her Toilet is well preserved, the blues in the curtain, the mother's skirt, and the cradle blanket in the Mauritshuis Young Mother are now a faded gray. See also Struik van der Loeff and Groen, "Restoration," 101, who first mention this discoloration of the ultramarine in the Young Mother.

${ }^{10}$ Jørgen Wadum, "Dou Doesn't Paint, Oh No, He Juggles with His Brush: Gerrit Dou, a Rembrandtesque Fijnschilder," ArtMatters 1 (2002): 62-77.

${ }^{11}$ For an overview of the paintings by Gerrit Dou in this group, see Arthur K. Wheelock Jr., ed., The Leiden Collection Catalogue (forthcoming; web publication, 2014, www.theleidencollection.com).

${ }^{12}$ For the attribution to Dou of an early painting in this group, Artist at his Easel (GD-112), dated to ca. 1630 (see fig. 66), as well as of Two Old Men Disputing (St. Peter and St) (GD-101), ca. 1630 (previously attributed to the circle of Rembrandt), and Elderly Man (GD-109), after 1640, another work initially thought to be in the circle of Dou, see Wheelock, The Leiden Collection Catalogue (see note 11 above).

${ }^{13}$ Refer to the Appendix for details of the methods employed. All X-radiographs, IR images, dendrochronological reports, and reports of John Twilley's analytical work are kept on file at the Leiden Collection.

${ }^{14}$ See Christoph Schölzel, “The Technique of the Leiden Fijnschilders," in The Leiden Fijnschilders from Dresden, ed. Annegret Laabs, exh. cat. (Dresden: Gemäldegalerie Alte Meister; Leiden: Museum De Lakenhal, 2000-2001), 16-24, esp. 16.

${ }^{15}$ For a discussion of the decline of the oak wood trade with the Baltic, mostly due to Polish-Swedish wars in 1626-29 and 1650-55, see Jo Kirby, "Studio Practice and the Training of Artists," in Art in the Making: Rembrandt, ed. David Bomford (New Haven: Yale University Press, 2006), 14-26, esp. 23.

${ }^{16}$ Ian Tyers, “Tree-Ring Analysis of Scholar Interrupted at His Writing, GD-102”, unpublished dendrochronological report, November 2010, curatorial files, The Leiden Collection: the tree 
rings match the Eastern Baltic reference data, and the youngest annual ring dates to 1592. This suggests an earliest possible felling date of 1601 with nine sapwood rings (minimum), and an earliest possible production date of 1603 (adding two years for seasoning and transport); a more likely felling date is 1607 with fifteen sapwood rings (median), and a more likely possible production date is 1609 (adding two years for seasoning and transport). In the following references to dendrochronological reports, only the youngest annual ring will be noted. Ian Tyers, "Tree-Ring Analysis of Portrait of a Lady with a Music Book, GD-116," unpublished dendrochronological report, November 2010, curatorial files, The Leiden Collection: the tree rings match the Eastern Baltic reference data, and the youngest annual ring dates to 1606, indicating a possible felling date.

${ }^{17}$ Ian Tyers, “Tree-Ring Analysis of Herring Seller and a Boy, GD-106," unpublished dendrochronological report, November 2010, curatorial files, The Leiden Collection: the tree rings match the German and French reference data, and the youngest annual ring dates to 1637 .

${ }^{18}$ Boersma, "Dou's Painting Technique," 58.

${ }^{19}$ Ian Tyers, "Tree-Ring Analysis ofScholar Interrupted at His Writing, GD-102" unpublished dendrochronological report, November 2010, curatorial files, The Leiden Collection: the youngest annual ring was formed in1592; Ian Tyers, "Tree-Ring Analysis of Goat in a Landscape, GD-114," unpublished dendrochronological report, November 2010, curatorial files, The Leiden Collection: the youngest annual ring was formed in 1586, and Ian Tyers, "Tree-Ring Analysis of Cat Crouching on the Ledge of an Artist's Atelier, GD-108," unpublished dendrochronological report, November 2010, curatorial files, The Leiden Collection: the youngest annual ring was formed in 1580 . ${ }^{20}$ Ian Tyers, "Tree-Ring Analysis of Cat Crouching on the Ledge of an Artist's Atelier, GD-108," unpublished dendrochronological report, November 2010, curatorial files, The Leiden Collection. It is important to note that these early dates may also be explained by the small size of the panels. Since small panels do not necessarily contain the whole width of a tree, only older wood from the center of the tree may be included.

${ }^{21}$ Ian Tyers, email communication, July 25, 2013, curatorial files, The Leiden Collection. The first wood sawmill in Leiden, De Ruyter, was most likely built in 1628, close to the Boshuizersluis, and it appears to have been the only one in Leiden during Dou's lifetime. The authors are grateful to Christiaan Vogelaar, email communication, July 31, 2013, for bringing De Ruyter to our attention; some information can be found on the Heritage website of the city of Leiden. (consulted July 31, 2013). By 1663, this mill was owned by the renowned Leiden carpenter Jan van Ackeren, who had worked on the design of the classicist Loridanshof, and whom Dou would have known personally. See the online Dutch windmill database, (consulted July 31, 2013): Van Ackeren gained permission to move his mill from the Boshuizersluis to the other side of the Haagweg, where transport possibilities were much better. It can be assumed that most Dou panels in the Leiden Collection were cut mechanically, presumably in such a mill, if not at De Ruyter itself.

${ }^{22}$ Kirby, "Studio Practice," 23: these craftsmen were members of the joiners' and cabinetmakers' guild. The administration of the Leiden guild of the joiners has not survived. The authors thank Piet Bakker, email communication, August 12, 2013, who conveyed that, based on his database research, at least 150 joiners and cabinetmakers are listed in Leiden in the seventeenth century. ${ }^{23}$ For a discussion on beveling, see Schölzel, “Technique," 16-17. See also Ernst van de Wetering, Rembrandt: The Painter at Work, rev. ed. (Amsterdam: Amsterdam University Press, 2009; first ed., 1997), 11.

${ }^{24}$ See Van de Wetering, Painter at Work, 11-12, for the discussion of beveling and the cutting of 
wood: panels had less tendency to warp when cut in this fashion.

${ }^{25}$ Panel-maker marks are often applied with a branding iron on the reverse of the panel, identifying the panel maker as well as the guild. For a discussion of paintings executed in Antwerp, where it appears to have been quite common to use such marks because of the regulations of the Antwerp guild of St. Luke, see Jørgen Wadum, “Recent Discoveriers on Antwerp Panel Makers' Marks," Technologia Artis (1993): 96-100.

${ }^{26}$ Kirby, "Studio Practice," 23.

${ }^{27}$ Van de Wetering, Painter at Work, 13: the clusters range from the smallest size of ca. $15.5 \mathrm{x} 12.7$ $\mathrm{cm}$, to the largest size of ca. 123.6 x $89.5 \mathrm{~cm}$. It is only when Rembrandt moved to Amsterdam that he stepped away from the somewhat restricted Leiden panel sizes and started to experiment with canvas and less standard panel sizes.

${ }^{28}$ Schölzel, "Technique," 24: here, the clusters range from the smallest size of ca. $26 \mathrm{x} 20 \mathrm{~cm}$ to the largest size of ca. $61 \times 45 \mathrm{~cm}$.

${ }^{29}$ Schölzel, “Technique," 24: note that this size falls into the second category on Van de Wetering's list (Van de Wetering's smallest category measures ca. $15.5 \times 12 \mathrm{~cm}$ ). Other panels from the Leiden Collection fall under Schölzel's categories four are ca. 33 x $26 \mathrm{~cm}$; five, ca. $43 \times 34 \mathrm{~cm}$, and six, ca. $61 \times 45 \mathrm{~cm}$.

${ }^{30}$ Schölzel, “Technique," 24: in the first group, Schölzel notes four paintings by Dou and one by Willem van Mieris. He also records one Dou in the third category, two in the fourth, three in the fifth, and one in the last category.

${ }^{31}$ See Ronni Baer, "Portrait of a Woman," in Gerrit Dou 1613-1675, exh. cat. (see note 1 above), 82-83, no. 10. See also Dominique Surh, "Portrait of a Lady in Profile," in The Leiden Collection Catalogue (see note 11 above), for her correspondence with Marieke de Winkel regarding clues about the dating based on the sitter's dress.

${ }^{32}$ Ian Tyers, "Tree-Ring Analysis of Portrait of a Lady in Profile, GD-110," unpublished dendrochronological report, November 2010, curatorial files, The Leiden Collection. Since the oval panel is firmly set into the larger panel, dendrochronological examination of the oval panel is not possible through traditional means at this time.

${ }^{33}$ See Anja K. Ševčík and Jiř́i Třeštík, "Doorstep Transactions: Structural and Compositional Transformations on Gerard Dou's Young Lady on a Balcony," Bulletin of the National Gallery in Prague 22-23 (2012-13): 23-43. For a partial list of these unusual constructions in Dou's oeuvre, see also Ronni Baer, "Of Cats and Dogs: Domestic Pets in Rembrandt and Dou," in Een Kroniek voor Jeroen Giltaij: Kroniek van het Rembrandthuis (Amsterdam: Rembrandthuis, 2012): 63-69, esp. 66, $67 \mathrm{n} \mathrm{16}$. For a survey of format changes, including inlaid panels, in the work of Dou's pupil Frans van Mieris, see Quentin Buvelot and Otto Naumann, "Format Changes in the Work by Frans van Mieris the Elder," Burlington Magazine 150 (2008): 102-4.

${ }^{34}$ John Twilley, "Scientific Examination of Portrait of Dirck van Beresteyn by Gerrit Dou (GD111)," unpublished report, dated February 23, 2012, curatorial files, The Leiden Collection.

For a recent publication on this painting, see Ronni Baer, "Dou and the Delft Connection: The Portrait of Dirk van Beresteyn," in Face Book: Studies on Dutch and Flemish Portraiture of the $16^{\text {th }}-18^{\text {th }}$ Centuries; Liber Amicorum Presented to Rudolf E. O. Ekkart on the Occasion of His $65^{\text {th }}$ Birthday, ed. Edwin Buijsen, Charles Dumas, and Volker Manuth (Leiden: Primavera Pers, 2012), 279-84.

${ }^{35}$ For a discussion of the possible function of this tiny portrait, see Dominique Surh, "Portrait of Dirck van Beresteyn," in The Leiden Collection Catalogue (see note 11 above). 
${ }^{36}$ Ernst van de Wetering cites a 1676 document preserved in the Leiden municipal archives, which provides an interesting case for suggesting that Leiden artists relied on the services of a single primer. The authors are grateful to Piet Bakker for providing a transcription of the passage (email communication, August 11, 2013) that clarifies the account. It appears that Dirck de Lorme (ca. 1635-ca. 1673) was the ebony worker (ebbenhoutwerker) who held the monopoly for priming canvases and panels in Leiden up until his death, and that Leendeert van Nes made the petition in 1676 to take over this service, rather than the other way around as described by Van de Wetering. See Van de Wetering, Painter at Work, 22 n 29. For other discussions of the ground layer during this period, see also Ashok Roy, "The Ground Layer: Function and Type," in Art in the Making: Rembrandt, ed. David Bomford (New Haven: Yale University Press, 2006), 27-29, esp. 27; and Melanie Gifford, "Lievens' Technique: 'Wonders in Smeared Paint, Varnishes, and Oils," in Jan Lievens: A Dutch Master Rediscovered, ed. Arthur K. Wheelock Jr., exh. cat. (Washington, D.C.: National Gallery of Art; Milwaukee Art Museum; Amsterdam: Rembrandthuis, 2008-9), 40-53, esp. 42.

${ }^{37}$ Struik van der Loeff and Groen, "Restoration,” and Boersma, "Dou’s Painting Technique," 58. ${ }^{38}$ Struik van der Loeff and Groen, "Restoration," 100.

${ }^{39}$ At the far right side of the Scholar Interrupted at His Writing, the area of the support bar of the globe is thinly painted and lies atop what appears to be the bare wood of the panel, visible through the craquelure. See John Twilley, "Scientific Examination of Scholar Interrupted at His Writing by Gerrit Dou (GD-102)," unpublished report dated April 2011, curatorial files, The Leiden Collection. In a painting from the early 1660s, Goat in a Landscape, the ground structure appears more uniform at the two sample locations taken in the areas of the sky and foliage. The ground layer recovered with both samples was based first upon lead white, followed by a thin $\tan$ stratum, rich in earth pigments, probably a primuersel. See John Twilley, "Scientific Examination of Goat in a Landscape by Gerrit Dou (GD-114)," unpublished report dated February 2013, curatorial files, The Leiden Collection.

${ }^{40}$ In the life of Hieronymous Bosch, Karel van Mander describes a primuersel as the transparent layer applied directly over the line underdrawing on top of the ground. Karel Van Mander, Het Schilder-Boeck (Haarlem: Paschier van Wesbysch, 1604), fol. 216v; for an English translation, see Karel van Mander, The Lives of the Illustrious Netherlandish and German Painters, from the First Edition of the 'Schilder-boeck' (1603-1604), trans. and ed. Hessel Miedema (Doornspijk: Davaco, 1994).

${ }^{41}$ Wadum, "Dou Doesn't Paint," 66. Wadum does not differentiate between the ground applied by the primer and the upper ground, or the primuersel, applied by the artist, and refers more generally to the ground as being light or buff colored.

${ }^{42}$ John Twilley, "Scientific Examination of Scholar Interrupted at His Writing by Gerrit Dou (GD102)," unpublished report dated April 2011, curatorial files, The Leiden Collection.

${ }^{43}$ John Twilley, "Scientific Examination of Goat in a Landscape by Gerrit Dou (GD-114)," unpublished report dated February 2013, curatorial files, The Leiden Collection.

${ }^{44}$ Wadum, "Dou doesn't paint," 65.

${ }^{45}$ For a list of paintings in which Wadum found partial, or fragmented, underdrawings, see Wadum, "Dou Doesn't Paint," 65-66.

${ }^{46}$ While carbon-based underdrawings are virtually absent in Rembrandt's painting, his own teacher, Pieter Lastman, seems to have executed preparatory underdrawings. An elaborate drawing was found in the infrared photograph of David and Uriah $(1619$, oil on panel, $41.6 \times 62.5 \mathrm{~cm}$; 
The Leiden Collection, New York, inv. no. PL-100). In this example, Lastman adhered closely to his initial conception and changed only a few minor details during the subsequent painting process, for instance, the position of the head of David's dog. See Annette Rupprecht, "Technical Notes of David and Uriah by Pieter Lastman, PL-100," unpublished report dated March 2012, curatorial files, The Leiden Collection, and Rachel Pollack, "David and Uriah by Pieter Lastman," in The Leiden Collection Catalogue (see note 11 above).

${ }^{47}$ In addition to the possibility of a medium lacking carbon black, another explanation for the appearance of Dou's "fragmented" underdrawings, could be that subsequent paint layers further obscure them. However, certain examples, such as the Hermit Praying, lack any areas that are obscured by IR-absorbing pigments and yet possess sketch lines prominent in some areas and absent in many others.

${ }^{48}$ The authors are thankful to Dr. Tico Seifert of the National Gallery of Scotland for confirming that similar line underdrawings were found in the window panes, figure, and in isolated areas of the tablecloth in Dou's earliest dated painting, the 1637 Violin Player (Edinburgh, National Gallery of Scotland), painted within a few years of the Scholar Interrupted, email communication, July 30, 2013. The authors are also grateful to Dr. Seifert for providing X-radiograph and IR photographs for study in July 2013. Groen and Struick van der Loeff indicated that the Young Mother at the Mauritshuis contains a clear underdrawing, most likely in carbon black along the folds of the mother's skirt. They noted that the lines appear uniform and were drawn as though guided by the straight edge of a ruler. Struik van der Loeff and Groen, "Restoration," 100-101. The authors would also like to thank Petria Noble of the Royal Cabinet of Paintings Mauritshuis for providing X-radiographs and IR photographs of Dou's 1658 Young Mother for study in July 2013.

${ }^{49}$ Here, however, the dark hatchings that appear in the IR photograph follow the final result of the paint layer so closely that it cannot be determined with absolute certainty whether the IR photograph reveals an underdrawing, and not the paint layers.

${ }^{50}$ According to Gerard de Lairesse's Het groot Schilderboeck of 1707, there are four stages in the painting process: "inventing," the "dead coloring," the second coloring or "working up," and the "retouching" or finishing. See Van de Wetering, Painter at Work, 27 n 43; David Bomford, "The Paint Layers," in Art in the Making: Rembrandt (see note 36 above), 30-34, esp. note 2.

${ }^{51}$ Wadum notes that Dou would "delineate the composition in bluntly applied brush strokes of varying thickness before spreading the undermodeling in monochrome hues." Wadum, "Dou Doesn't Paint," 67. In Rembrandt's Concord of the State, from ca. 1640 (Rotterdam, Museum Boijmans van Beuningen), an underlying compositional sketch was found, which Van de Wetering cites as an example of Rembrandt's laying in simultaneously the monochrome dead coloring with a sketch in a "provisionally completed whole." Van de Wetering, Painter at Work, 27. Thus it seems plausible that Dou may have also handled the sketch phase as synonymous with the dead coloring.

52 Wadum, “Dou Doesn't Paint," 67.

${ }^{53}$ John Twilley, "Scientific Examination of An Old Scholar Sharpening a Quill by Gerrit Dou (GD104)," unpublished report dated January 2013, curatorial files, The Leiden Collection.

${ }^{54}$ For a discussion about the pigment samples and their cross sections, see John Twilley, "Scientific Examination of Goat in a Landscape by Gerrit Dou (GD-114)," unpublished report dated February 2013, curatorial files, The Leiden Collection. For a general technical overview with notes about its recent conservation history, see Annette Rupprecht, "Technical Notes of Goat in a Landscape by Gerrit Dou, GD-114," unpublished report dated August 2011, curatorial files, The 
Leiden Collection.

55 There was seldom the opportunity to take cross sections for stratigraphic analysis in important areas of the compositions and, accordingly, pigment identifications are more numerous from the uppermost layers or more heavily painted areas. Cross sections were prepared when feasible.

${ }^{56}$ Raman spectroscopy, often highly effective on isolated pigments, is seldom successful on embedded cross sections of dried oil paint. The sample quantities required for chromatographic methods of lake pigment identification were unacceptable for these small paintings.

${ }^{57}$ Lead-fatty acid soaps are the reaction products of lead, derived from lead-based pigments, interacting with free fatty acids, liberated from the drying oils in the medium. Over time, small nodules of these products may erupt from the paint surface, giving rise to minute blemishes that catch and scatter the light. Even when not visible on the paint surface their development was frequently noted during laboratory study.

${ }^{58}$ The alteration of smalt occurs by decomposition of the powdered glass of which it is composed, usually with the loss of the cobalt responsible for its color. The process proceeds from the exterior to the interior of each individual grain so that small particles may be affected throughout, while coarse ones acquire a "rind" from which the color has been lost around an intact core. Neither condition was evident in the samples from this painting, which retain brilliant saturated color throughout a wide range of particle sizes. Discussions of the forms of smalt alteration, its underlying causes and the means of its recognition can be found in the following references: Laurianne Robinet, Marika Spring, and Sandrine Pages-Camagna, "Vibrational Spectroscopy Correlated with Elemental Analysis for the Investigation of Smalt Pigment and Its Alteration in Paintings," Analytical Methods 5 (2013): 4628-38 http://dx.doi.org/10.1039/c3ay40906f; Jaap J. Boon et al., "Imaging Microspectroscopic, Secondary Ion Mass Spectrometric and Electron Microscopic Studies on Discoloured and Partially Discoloured Smalt in Cross sections of $16^{\text {th }}$-Century Paintings," Chimia 55 (2001): 952-60.

${ }^{59}$ E.-L. Richter, "Seltene Pigmente im Mittelalter," Zeitschrift für Kunsttechnologie und Konservierung 2 (1988): 171-77; Mark Richter, "Shedding Some New Light on the Blue Pigment 'Vivianite' in Technical Documentary Sources of Northern Europe," ArtMatters 4 (2007): 37-53; H. Stege et al., "Vivianit -- Neue Nachweise des Pigmentes und seine charakteristischen Veränderungen in der niederländischen Malerei des 17. Jahrhunderts," in Archäometrie und Denkmalpflege -- Kurzberichte, ed. O. Hahn and H. Stege, (Bochum: Bergbau-Museum Bochum, 2006), 81-83.

${ }^{60}$ Vivianite has long been known to undergo oxidation of its iron accompanied by the breakdown of the crystallinity of the mineral. T. L. Watson, "The Colour Change in Vivianite and Its Effects on the Optical Properties," American Mineralogist 3 (1918): 159-61; John Twilley, "Polychrome Decorations on Far Eastern Gilt Bronze Sculpture of the Eighth Century," in Scientific Research on the Sculptural Arts of Asia: Proceedings of the Third Forbes Symposium at the Freer Gallery of Art, eds. Janet G. Douglas, Paul Jett, and John Winter (London: Archetype, 2007), 174-87 (Figures $10 \mathrm{a}, \mathrm{e}$, and $\mathrm{f}$ in this reference show the dramatic color change associated with the alteration of paint consisting solely of vivianite); J. O. Nriagu, "Stability of Vivianite and Ion-Pair Formation in the System Fe3(PO4)2-H3PO4-H2O," Geochimica et Cosmochimica Acta 36 (1972): 459-70 http://dx.doi.org/10.1016/0016-7037(72)90035-X ; David A. Scott and Gerhard Eggert, "The Vicissitudes of Vivianite as Pigment and Corrosion Product," Reviews in Conservation 8 (2007): 3-13. The concept that all iron phosphate pigment occurrences constitute "vivianite" is an oversimplification, since the mineralogical literature describes several related, but distinct, compounds including metavivianite and ferrostrunzite. While these contain some ferric iron and 
often possess colors ranging from blue to brown, testing by methods capable of distinguishing between these iron phosphates has shown that metavivianite has also been employed in painting and can sometimes retain a blue color. See Hartmut Kutzke et al., "Alteration of Vivianite Pigments in Paint Layers of $17^{\text {th }}$ Century Oil Paintings," ESRF Experiment \#ME-1199, March 1, 2006 (http:ftp.esrf.eu/pub/UserReports/32509_A.pdf; accessed, February 3, 2011). The authors cite the occurrence of vivianite in a sample from Dou's 1646 The Praying Anchorite. While artists of the seventeenth century lacked the means to fully know or control what was in their pigments, we can expect that someone devoting the attention to his work that Dou displays would have been very selective in choosing among these highly variable materials.

${ }^{61}$ Margriet van Eikema Hommes, "Indigo as a Pigment in Oil Painting and Its Fading Problems," in Changing Pictures: Discoloration in $15^{\text {th }}-17^{\text {th }}$ Century Oil Paintings (London: Archetype, 2004). ${ }^{62}$ The pervasive application of such a costly pigment may reflect the preference of the painting's original owner, Johan de Bye. For a discussion of the painting, its meaning, and early ownership by De Bye, see Dominique Surh, “Goat in a Landscape," in The Leiden Collection Catalogue (see note 11 above).

${ }^{63}$ John Twilley, "Scientific Examination of Goat in a Landscape by Gerrit Dou (GD-114)," unpublished report dated February 2013, curatorial files, The Leiden Collection.

${ }^{64} \mathrm{~A}$ "lake" pigment is composed of soluble organic color of the type used in the dyeing of fabric that has been immobilized on a colorless carrier such as chalk, alumina, or gypsum so that it can function as a pigment. Lakes are typically less resistant to light-fading than mineral pigments. ${ }^{65}$ The color saturation of this yellow was low in all places where it occurs, even those beneath opaque layers that could be expected to have sheltered it from fading. These lower layers, which comprise a yellow application covered over by the leaf that was not part of its construction, were not intended to influence the layers above. Differentiation of all strata comprising the foliage sample required the application of all four methods of sample preparation illustrated in figure $39 \mathrm{a}-\mathrm{d}$. However, it was impossible to isolate any examples of the yellow lake for other forms of analysis or, often, to differentiate the lake from its neighbors during scanning electron microscopy. No lead-tin yellow or orpiment was found in the yellows. John Twilley, "Scientific Examination of Goat in a Landscape by Gerrit Dou (GD-114)," unpublished report dated February 2013, curatorial files, The Leiden Collection.

${ }^{66}$ For an overview of Rembrandt's similar working order, which follows a widespread practice in the seventeenth century, see Van de Wetering, Rembrandt: The Painter at Work, 32-44, 45 n 54.

${ }^{67}$ For an example of Dou leaving an area unpainted in reserve, see John Twilley, "Scientific Examination of Cat Crouching on the Ledge of an Artist's Atelier by Gerrit Dou (GD-108)," unpublished report dated December 2013, curatorial files, The Leiden Collection.

${ }^{68}$ For a detailed account of the sequence of painting in this area as indicated by the overlapping layers of paint, see John Twilley, "Scientific Examination of Young Woman Holding a Parrot by Gerrit Dou (GD-105)," unpublished report dated February 2014, curatorial files, The Leiden Collection.

${ }^{69}$ Baer, “The Paintings of Gerrit Dou," nos. 113, 116; Baer, Gerrit Dou 1613-1675, 112, 130, 132;Sluijter, Lof der schilderkunst, 58; Wadum, “Dou Doesn't Paint," 68-69.

${ }^{70}$ Wadum, "Dou Doesn't Paint," 68-69.

${ }^{71}$ John Twilley, "Scientific Examination of Scholar Interrupted at His Writing by Gerrit Dou (GD102)," unpublished report dated April 2011, curatorial files, The Leiden Collection. It is unclear which word is partially represented; for a fuller discussion of the iconography, see Dominique 
Surh, "Scholar Interrupted at His Writing" in The Leiden Collection Catalogue (see note 11 above).

${ }^{72}$ The X-radiograph indicates that the rectangular composition was initially conceived as an arched top. The greater visibility of the arch along the upper right-hand side coincides with the direction of the fall of light onto this area and accounts for the greater content of lead white in the underlying paint. Dou seems to have positioned the figure centrally underneath this arch, and when he later added the asymmetrical curtain, he shifted the figure to the right in order to allow for a more even distribution of background space surrounding the woman's head. See Dominique Surh, "Portrait of a Lady with a Music Book," in The Leiden Collection Catalogue (see note 11 above).

${ }^{73}$ Annette Rupprecht, "Technical Notes of Old Woman at a Niche by Candlelight by Gerrit Dou, GD-103," unpublished report dated March 2012, curatorial files, The Leiden Collection, has noted a slightly raised triangular shape near the base of the old woman's left hand where the artist painted the top of the oil lamp, visible in the X-radiograph, and infrared photograph, as well as in the raking light photograph.

${ }^{74}$ A similar oil lamp is also found in Gerrit Dou's Old Woman with Two Young Children, ca. 1655, (Boston, Museum of Fine Arts), see Ronni Baer, "A Dou for Boston," in Collected Opinions: Essays on Netherlandish Art in Honour of Alfred Bader, eds. Volker Manuth and Axel Rüger (London: Paul Holberton, 2004), 18-25, esp. 21.

${ }^{75}$ Baer, "The Paintings of Gerrit Dou," no. 14; Ronni Baer, "Man Interrupted at His Writing," in Gerrit Dou 1613-1675, exh. cat. (see note 1 above), 70-71, no. 4.

${ }^{76}$ For an overview of Dou's depictions of the artist at work, see R. W. Hunnewell, "Gerrit Dou's Self Portraits and Depictions of the Artist" (PhD diss., Boston University, 1983).

${ }^{77}$ For a discussion of the attribution history of the Artist at His Easel, ca. 1630, oil on panel, 66.7 x $50.8 \mathrm{~cm}$; The Leiden Collection (GD-112), see Dominique Surh, "Artist at His Easel," in The Leiden Collection Catalogue (see note 11 above). Two other paintings with similar subject matter are illustrated in Gerrit Dou 1613-1675, exh. cat. (see note 1 above), 64-65, no. 1; 68-69, no. 3. ${ }^{78}$ A parasol frequently appears in Dou's later paintings, particularly in his own self-portraits, in conjunction with an easel in the background; for example, his Self-Portrait of 1647 in the Dresden Gemäldegalerie Alte Meister. A parasol also appears in The Quack in the Boijmans Museum in Rotterdam to highlight the subject, who performs to an audience of gullible listeners. On the parallel between the artist and the quack in working deception, see J. A. Emmens, "De Kwakzalver: Gerrit Dou (1613-1675)," Openbaar Kunstbezit 15 (1971): 4a-b; Ivan Gaskell, "Gerrit Dou, His Patrons and the Art of Painting," Oxford Art Journal 5, no. 1 (March 1982): 18-20 http://dx.doi. org/10.1093/oxartj/5.1.15; and Svetlana Alpers, The Art of Describing (Chicago: University of Chicago Press, 1983), 116-18. It is not clear whether Dou's inclusion of the parasol in the Scholar Interrupted at His Writing is also a reference to deception.

${ }^{79}$ In his 2002 publication, Jørgum Wadum observed that in an earlier composition the large book in the Scholar Interrupted at His Writing was originally planned to lie flat on the table. Our $\mathrm{X}$-radiograph and IR photograph (at 1500 nanometers) does not indicate any such change in the position of the book, so it remains unclear as to what his comment precisely refers. Nevertheless, his explanation does address some of the otherwise perplexing changes that consist of broad features seen in IR photography in the bottom foreground that have no parallels in the final painting. See Wadum, “Dou Doesn't Paint," 69 n 46.

${ }^{80}$ Annette Rupprecht, “Technical Notes of Scholar Interrupted at His Writing by Gerrit Dou, GD102," unpublished report dated March 2011, curatorial files, The Leiden Collection. 
${ }^{81}$ Baer mentions the possible influence of Rembrandt in his portraits from the early 1630 s, where he placed his signature in a letter or paper held by the subject; see Ronni Baer, "Man Interrupted at His Writing," in Gerrit Dou 1613-1675, exh. cat. (see note 1 above), 70-71, no. 4 n 4, 136. ${ }^{82}$ See Junko Aono, "Boy with a Mousetrap by Candlelight by Dominicus van Tol," in The Leiden Collection Catalogue (see note 11 above), in which a boy holds a similar mousetrap with a diagonal lever at the top that would have controlled the trapping mechanism.

${ }^{83}$ Baer suggests that the young woman originally belonged to a separate composition and that when she was painted out, the cat and the curtain were painted in. She speculates that the young woman was intended as part of an independent kitchen scene and was shown leaning forward to pour from a jug. For Dou's earlier treatment of the subject in Kitchen Scene, late 1640s, oil on panel, 41.3 x $30.5 \mathrm{~cm}$; Copenhagen, Statens Museum for Kunst, and The Mousetrap, ca. 1650, signed, oil on panel 47 x $36 \mathrm{~cm}$; Montpellier, Musée Fabre, and Girl with a Cat and Mousetrap (formerly Sotheby's, London, July 3, 2013, no. 13; now with Adam Williams, New York), see Ronni Baer, "Of Cats and Dogs," 67-68, 69 n 19, fig. 4.

${ }^{84}$ The image of a cat watching a mousetrap first appeared in Daniel Heinsius's popular book of love emblems from 1608, Emblemata amatoria, where it symbolized the ensnarement of love, with the weary, trapped mouse representing the love-struck soul and the cat embodying the lust that ultimately does in its prey. Heinsius's twentieth emblem depicts a mouse inside a wooden trap, too frightened to come out for fear of the lurking cat who keeps watch beside it, while a mischievous Cupid with his bow and arrow iterates the underlying theme of love. Daniel Heinsius, Emblemata Amatoria (Amsterdam, 1608), fol. 20. For a fuller discussion of the iconography, see Dominique Surh, "Cat Crouching on the Ledge of an Artist's Atelier" in The Leiden Collection Catalogue (see note 11 above).

${ }^{85}$ Neither the ground nor the paint layer itself extends over the edges of the panel. See Annette Rupprecht, "Technical Notes of Cat Crouching on the Ledge of an Artist's Atelier by Gerrit Dou GD-108," unpublished report dated March 2012, curatorial files, The Leiden Collection.

${ }^{86}$ Left in reserve, the globe itself appears not to have been painted but merely planned. See John Twilley, "Scientific Examination of Cat Crouching on the Ledge of an Artist's Atelier by Gerrit Dou (GD-108)," unpublished report dated December 2013, curatorial files, The Leiden Collection.

${ }^{87}$ Cat Crouching on the Ledge of an Artist's Atelier is unusual in its iconographic simplicity. Baer has observed that the tail of a mouse emerges from underneath the proper left paw of the cat, but this observation appears to be a misreading of an area of exposed ground where two areas of dark paint originally conjoined. See Baer, "Of Cats and Dogs," 66.

${ }^{88}$ Eric Jan Sluijter, "Venus, Visus, and Pictura," in Seductress of Sight: Studies in Dutch Art of the Golden Age (Zwolle: Waanders, 2000), 87-159, esp. 90-99.

${ }^{89}$ For a similar interpretation, see Baer, "Of Cats and Dogs," 66-69. On the wide range of meanings associated with the representation of the cat in the seventeenth century, see Susan Donahue Kuretsky, "Rembrandt's Cat," in Aemulatio Imitation: Emulation and Invention in Netherlandish Art from 1500 to 1800; Essays in Honor of Eric Jan Sluijter, ed. Anton W. A. Boschloo, Nicolette C. Sluijter-Seijffert, Jacquelyn N. Coutre, and Stephanie S. Dickey (Zwolle: Waanders, 2011), 263-76.

\section{Bibliography}

Alpers, Svetlana. The Art of Describing. Chicago: University of Chicago Press, 1983. 
Aono, Junko. "Boy with a Mousetrap by Candlelight by Dominicus van Tol.” In the Leiden Collection Catalogue, edited by Arthur K. Wheelock Jr. Online publication, forthcoming, 2014, www. theleidencollection.com.

Baer, Ronni. “A Dou for Boston.” In Collected Opinions: Essays on Netherlandish Art in Honour of Alfred Bader, edited by Volker Manuth and Axel Rüger, 18-25.London: Paul Holberton, 2004.

Baer, Ronni. "Dou and the Delft Connection: The Portrait of Dirk van Beresteyn." In Face Book: Studies on Dutch and Flemish Portraiture of the $16^{\text {th }}-18^{\text {th }}$ Centuries; Liber Amicorum Presented to Rudolf E. O. Ekkart on the Occasion of His $65^{\text {th }}$ Birthday, edited by Edwin Buijsen, Charles Dumas, and Volker Manuth, 279-84. Leiden: Primavera Pers, 2012.

Baer, Ronni.Gerrit Dou 1613-1675: A Master in the Age of Rembrandt. Exh. cat. Washington, D.C.: National Gallery of Art; London: Dulwich Picture Gallery; The Hague: Royal Cabinet of Paintings Mauritshuis, 2000-2001 / New Haven: Yale University Press, 2000.

Baer, Ronni. "Man Interrupted at His Writing." In Gerrit Dou 1613-1675: A Master in the Age of Rembrandt, 70-71, no. 4 (see above).

Baer, Ronni. "Of Cats and Dogs: Domestic Pets in Rembrandt and Dou." In Een Kroniek voor Jeroen Giltaij: Kroniek van het Rembrandthuis (Amsterdam: Rembrandthuis, 2012), 63-69.

Baer, Ronni. "Portrait of a Woman.” In Gerrit Dou 1613-1675: A Master in the Age of Rembrandt, 82-83, no. 10 (see above).

Baer, Ronni. “The Paintings of Gerrit Dou (1613-1675).” PhD diss., New York University, 1990.

Boersma, Annetje. “Dou’s Painting Technique: An Examination of Two Paintings." In Baer, Ronni, Gerrit Dou 1613-1675: A Master in the Age of Rembrandt, 54-63 (seeabove).

Bomford, David. “The Paint Layers." In Art in the Making: Rembrandt, edited by David Bomford, 30-34. New Haven: Yale University Press, 2006.

Boon, Jaap J., et al. "Imaging Microspectroscopic, Secondary Ion Mass Spectrometric and Electron Microscopic Studies on Discoloured and Partially Discoloured Smalt in Cross sections of $16^{\text {th }}$-Century Paintings." Chimia 55 (2001): 952-60.

Buvelot, Quentin, and Otto Naumann. "Format Changes in the Work by Frans van Mieris the Elder." Burlington Magazine 150 (2008): 102-4.

Eikema Hommes, Margriet van. "Indigo as a Pigment in Oil Painting and Its Fading Problems." In Changing Pictures, Discoloration in $15^{\text {th }}-17^{\text {th }}$ Century Oil Paintings. London: Archetype, 2004.

Emmens, J. A. “De Kwakzalver: Gerrit Dou (1613-1675).” Openbaar Kunstbezit 15 (1971): 4a-b. 
Gaskell, Ivan. "Gerrit Dou, His Patrons and the Art of Painting." Oxford Art Journal 5, no. 1 (March, 1982): 18-20. http://dx.doi.org/10.1093/oxartj/5.1.15

Gifford, Melanie. “Lievens' Technique: 'Wonders in Smeared Paint, Varnishes, and Oils." In Jan Lievens:A Dutch Master Rediscovered, edited by Arthur K. Wheelock Jr., 40-53. Washington, D.C.: National Gallery of Art, 2008.

Heinsius, Daniel. Emblemata Amatoria. Amsterdam, 1608.

Hunnewell, R. W. “Gerrit Dou's Self Portraits and Depictions of the Artist.” PhD diss., Boston University, 1983.

Kirby, Jo. "Studio Practice and the Training of Artists." In Art in the Making: Rembrandt, edited by David Bomford, 14-26. New Haven: Yale University Press, 2006.

Kuretsky, Susan Donahue. "Rembrandt's Cat.” In Aemulatio Imitation: Emulation and Invention in Netherlandish Art from 1500 to 1800; Essays in Honor of Eric Jan Sluijter, edited by Anton W.

A. Boschloo, Nicolette C. Sluijter-Seijffert, Jacquelyn N. Coutre, and Stephanie S. Dickey, 263-76. Zwolle: Waanders, 2011.

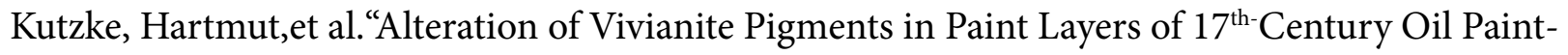
ings." ESRF Experiment \#ME-1199 (March 1, 2006; http: ftp.esrf.eu/pub/UserReports/32509_A. pdf; accessed, February 3, 2011).

Lammertse, Friso. "Veranderen na verloop van jaren: Over Gerard Dou’s Kwakzalver in Rotterdam en het Zelfportret in Kansas City." In Album Discipulorum J. R. J. van Asperen de Boer, edited by Peter van den Brink and Liesbeth M. Helmus, 111-20. Zwolle: Waanders, 1997.

Mander, Karel van. Het Schilder-Boeck. Haarlem: Paschier van Wesbysch, 1604.

Mander, Karel van. The Lives of the Illustrious Netherlandish and German Painters, from the first edition of the "Schilder-boeck" (1603-1604.) Edited and translated by Hessel Miedema. Doornspijk: Davaco, 1994.

Nriagu, J. O. "Stability of Vivianite and Ion-Pair Formation in the System $\mathrm{Fe}_{3}(\mathrm{PO} 4)_{2}-\mathrm{H}_{3} \mathrm{PO}_{4}-$ $\mathrm{H}_{2} \mathrm{O}$." Geochimica et Cosmochimica Acta 36 (1972): 459-70. http://dx.doi.org/10.1016/00167037(72)90035-X

Pollack, Rachel. "David and Uriah by Pieter Lastman.” In the Leiden Collection Catalogue, edited by Arthur K. Wheelock Jr. Online publication, forthcoming, 2014, www.theleidencollection.com.

Richter, E.-L. “Seltene Pigmente im Mittelalter.” Zeitschrift für Kunsttechnologie und Konservierung 2 (1988): 171-77.

Richter, Mark. "Shedding Some New Light on the Blue Pigment 'Vivianite' in Technical Docu- 
mentary Sources of Northern Europe." ArtMatters 4 (2007): 37-53.

Robinet, Laurianne, Marika Spring, and Sandrine Pages-Camagna. "Vibrational Spectroscopy Correlated with Elemental Analysis for the Investigation of Smalt Pigment and its Alteration in Paintings." Analytical Methods 5 (2013): 4628-38. http://dx.doi.org/10.1039/c3ay40906f

Roy, Ashok. "The Ground Layer: Function and Type." In Art in the Making: Rembrandt, edited by David Bomford, 27-29. New Haven: Yale University Press, 2006.

Schölzel, Christoph. “The Technique of the Leiden Fijnschilders.” In The Leiden Fijnschilders From Dresden, edited by Annegret Laabs, 16-24. Exh. cat. Dresden: Gemäldegalerie Alte Meister; Leiden: Museum de Lakenhal / Zwolle: Waanders, 2000.

Ševčík, Anja K., and JiříTřeštík. "Doorstep Transactions: Structural and Compositional Transformations on Gerard Dou's Young Lady on a Balcony." Bulletin of the National Gallery in Prague22-23 (2012-13): 23-43.

Scott, David A., and Gerhard Eggert. "The Vicissitudes of Vivianite as Pigment and Corrosion Product." Reviews in Conservation 8 (2007): 3-13.

Sluijter, Eric Jan. De lof der schilderkunst: Over schilderijen van Gerrit Dou (1613-1675) en een traktaat van Philips Angel uit 1642. Hilversum: Verloren, 1993.

Sluijter, Eric Jan. "Venus, Visus, and Pictura." In Seductress of Sight: Studies in Dutch Art of the Golden Age, edited by Eric Jan Sluijter, 87-159. Zwolle: Waanders, 2000.

Stege, H., et al. "Vivianit - Neue Nachweise des Pigmentes und seine charakteristischen Veränderungen in der niederländischen Malerei des 17. Jahrhunderts.” In Archäometrie und Denkmalpflege - Kurzberichte, edited by O. Hahn and H. Stege, 81-83. Bochum: Bergbau-Museum Bochum, 2006.

Struick van der Loeff, Luuk, and Karin Groen. "Probleem, Overwegingen en Beslissingen bij de Conservatie en Restauratie van het Schilderij door Gerard Dou 'Jonge Moeder', Mauritshuis, 1658, inv. nr. 32." Centraal Laboratorium Themadag 12 (1987): 40-50.

Struick van der Loeff, Luuk, and Karin Groen. "The Restoration and Technical Examination of Gerard Dou's Young Mother in the Mauritshuis." In ICOM Committee for Conservation: $10^{\text {th }}$ Triennial meeting, Washington, DC, edited by Janet Bridgland, 98-103. Lawrence, Kansas: Allen Press, 1993.

Surh, Dominique. “An Artist at His Easel." In the Leiden Collection Catalogue, edited by Arthur K. Wheelock, Jr. Online publication, forthcoming, 2014, www.theleidencollection.com.

Surh, Dominique. "Cat Crouching on the Ledge of an Artist's Atelier." In the Leiden Collection Catalogue, edited by Arthur K. Wheelock Jr. Online publication, forthcoming, 2014, www.thelei- 


\section{dencollection.com.}

Surh, Dominique. "Goat in a Landscape." In the Leiden Collection Catalogue, edited by Arthur K. Wheelock Jr. Online publication, forthcoming, 2014, www.theleidencollection.com.

Surh, Dominique. "Portrait of Dirck van Beresteyn." In the Leiden Collection Catalogue, edited by Arthur K. Wheelock, Jr. Online publication, forthcoming, 2014, www.theleidencollection.com

Surh, Dominique. "Portrait of a Lady in Profile." In the Leiden Collection Catalogue, edited by Arthur K. Wheelock Jr. Online publication, forthcoming, 2014, www.theleidencollection.com.

Surh, Dominique. "Portrait of a Lady with a Music Book." In the Leiden Collection Catalogue, edited by Arthur K. Wheelock Jr. Online publication, forthcoming, 2014, www.theleidencollection. com.

Surh, Dominique. "Scholar Interrupted at His Writing." In the Leiden Collection Catalogue, edited by Arthur K. Wheelock Jr. Online publication, forthcoming, 2014, www.theleidencollection.com.

Twilley, John. "Polychrome Decorations on Far Eastern Gilt Bronze Sculpture of the Eighth Century." In Scientific Research on the Sculptural Arts of Asia: Proceedings of the Third Forbes Symposium at the Freer Gallery of Art, edited by Janet G. Douglas, Paul Jett, and John Winter, 174-87. London: Archetype, 2007.

Wadum, Jørgen. “Recent Discoveriers on Antwerp Panel Makers’ Marks.” Technologia Artis (1993): 96-100.

Wadum, Jørgen. “Dou Doesn't Paint, Oh No, He Juggles with His Brush: Gerrit Dou, a Rembrandtesque Fijnschilder.” ArtMatters 1 (2002): 62-77.

Watson, T. L. "The Colour Change in Vivianite and Its Effects on the Optical Properties." American Mineralogist 3 (1918): 159-61.

Wetering, Ernst van de. Rembrandt: The Painter at Work. Rev. ed. Amsterdam: Amsterdam University Press, 2009; first ed., 1997.

Wheelock, Arthur K., Jr. “Dou’s Reputation.” In Ronni Baer, Gerrit Dou 1613-1675: A Master in the Age of Rembrandt, 12-24 (see above).

Wheelock, Arthur K., Jr., ed. The Leiden Collection Catalogue. Online publication, forthcoming, 2014, www.theleidencollection.com.

\section{Recommended citation:}

Dominique Surh, Ilona van Tuinen, John Twilley, "Insights from Technical Analysis on a Group of Paintings by Gerrit Dou in the Leiden Collection," JHNA 6:1 (Winter 2014), D0l:10.5092/jhna.2014.6.1.3 